\title{
A UAV- and field-based investigation of the land degradation and soil erosion at opencast coal mine dumps after 5 years' evolution of natural processes
}

\section{Wu Xiao}

Zhejiang University

He Ren

China University of Mining and Technology - Beijing Campus https://orcid.org/0000-0003-1616-4336

Tao Sui

China University of Mining and Technology - Beijing Campus

Heyu Zhang

Guangzhou South China Insititue of Natural Resources Science and Technoloy

Yanling Zhao

China University of Mining and Technology - Beijing Campus

Zhenqi Hu ( $\square$ huzq1963@163.com )

China University of Mining and Technology

\section{Research}

Keywords: open-pit mining, dumps, ecological restoration, UAV, soil erosion, ecosystem stability, geograph-ical detector

Posted Date: May 25th, 2021

DOl: https://doi.org/10.21203/rs.3.rs-548511/v1

License: (c) (i) This work is licensed under a Creative Commons Attribution 4.0 International License.

Read Full License 


\section{A UAV- and field-based investigation of the land degradation and soil}

2

3

\section{erosion at opencast coal mine dumps after 5 years' evolution of natural}

\section{processes}

Wu Xiao ${ }^{1,2}, \mathrm{He} \mathrm{Ren}^{2}$, Tao Sui ${ }^{2}$, Heyu Zhang ${ }^{3}$, Yanling Zhao ${ }^{2}$, Zhenqi $\mathrm{Hu}^{2 *}$

1. Department of land management, Zhejiang University, Hangzhou, 310058, China.

2. Institute of Land Reclamation and Ecological Restoration, China University of Mining and Technology, Beijing, 100083, China

3. Guangzhou South China Institute of Natural Resources Science and Technology, Guangzhou, 510642, China

Corresponding author email: huzq1963@163.com

Abstract:

Open-pit coal mining has a large impact on land surface, both at the mining pits themselves and at waste sites. After artificial management is stopped, a reclaimed opencast coal mine dump is affected by wind and water erosion from natural processes, resulting in land degradation and even safety incidents. In this paper, the soil erosion and land degradation after 5 years of such natural processes, at the Xilinhot open pit coal mine dump in Inner Mongolia, were investigated. A multisource data acquisition method was applied: the vegetation coverage index was extracted from GF1 satellite imagery, high-precision terrain characteristics and the location and degree of soil erosion were obtained using an Unmanned Aerial Vehicle (UAV), and the physical properties of the topsoil were obtained by field sampling. On this basis, the degree and spatial distribution of erosion cracks were identified, and the causes of soil erosion and land degradation were analyzed using a geographical detector. The results show that: 1) The multi-source data acquisition method can provide effective basic data for the quantitative evaluation of the ecological environment at dumps; 2) slope aspect and vegetation fractional coverage are the main factors affecting the degree of degradation and soil erosion. Based on this analysis, several countermeasures are proposed to mitigate land degradation: 1) The windward slope be designed to imitate the natural landform; 2) engineering measures should be applied at the slope to restrain soil erosion; 3) pioneer plants should be widely planted on the platform at the early stage of reclamation.

Keywords: open-pit mining, dumps, ecological restoration, UAV, soil erosion, ecosystem stability, geographical detector

\section{Introduction}


Surface mining is the most widely used mining method in the world. In the United States, Germany, Australia, Russia and other developed countries, the proportion of opencast mining reached more than $60 \%$. Although surface mining has many advantages, such as high safety, high mining efficiency, high recovery rate, low cost and etc. (Kenndey, 1990), it drastically damages the eco-environment and produces a large amount of coal waste. The dump formed by the resulting coal waste stack takes up a large area of land, where the surface soil is poor and it is pressed by heavy trucks, resulting in problems for plant roots and an increase in surface runoff. During the rainy season, concentrated precipitation flows into the settlement cracks, causing disasters such as collapse, landslide and debris flow, and seriously threatening the lives of residents nearby (Neugirg et al., 2016). Statistically, the land used for open-pit mine dumps accounts for $30 \%-50 \%$ of the total land used for mining. As a large coal mining country, China's raw coal production accounts for more than $70 \%$ of its total energy production (National Bureau of Statistics, 2017). There are a large number of shallow coal seams in western China. The mining conditions are good and the coal quality is excellent. The center of coal mining is predicted to move gradually westwards (Guo et al., 2018). The proportion of open-pit production also increase gradually, from about 3.3\% in 1998 to about $15 \%$ in 2015 (Huang et al., 2015) and the annual output of coal is expected to reach $3.9 \times 10^{9}$ tons by 2020. The average annual additional land area occupied is up to $1 \times 10^{4} \mathrm{hm}^{2}\left(10^{8} \mathrm{~m}^{2}\right)$, and the soil erosion area increases annually by $3 \times 10^{3} \mathrm{hm}^{2}\left(3 \times 10^{7} \mathrm{~m}^{2}\right)$ (Qi, 2017).Therefore, it is important to take account of the safety and stability of the dump when assessing the production safety and economic benefits of the open mining area. The monitoring and maintenance of the dump has become an important aspect of the reclamation process of the open mining area.

The dump is mainly composed of waste material from open-pit mining. After the dump reaches its full capacity, it is covered with a layer of topsoil to ensure a rapid restoration of vegetation. The construction of the dump needs to be adapted to local conditions, and the appropriate disposal method should be selected according to the geomorphologic characteristics of the mining area. Several types can be distinguished, such as conical waste dump, piles type of shape, board shape, shape of the terrace, shape of slope, ridge shape, straight shape, or they may take the form of flat coverings. (Petra et al., 2015). Because of the high cost of land acquisition in China, flat coverings are rarely used in filling the dumps. The terraced landform of the Loess plateau can be imitated by designing terraced dumps with a relative height difference of $100 \mathrm{~m}-150 \mathrm{~m}$ between the platform and the slope intersect (Fig. 1a). Alternatively, in hill and gully regions of the Loess plateau, fly ash and gangue can be used to carry out a mixed ecological filling of the open pit and gully (Fig. 1b), laying a foundation for subsequent ecological restoration (Shanxi provincial bureau of quality and technical supervision, 2016). However, in the eastern grassland area of northern China, the terrain is flat, there is an insufficient supply of topsoil, and the precipitation can be highly intense. In order to reduce the amount of land they occupy, most dumps adopt a ladder distribution (Liu et al., 2011). 


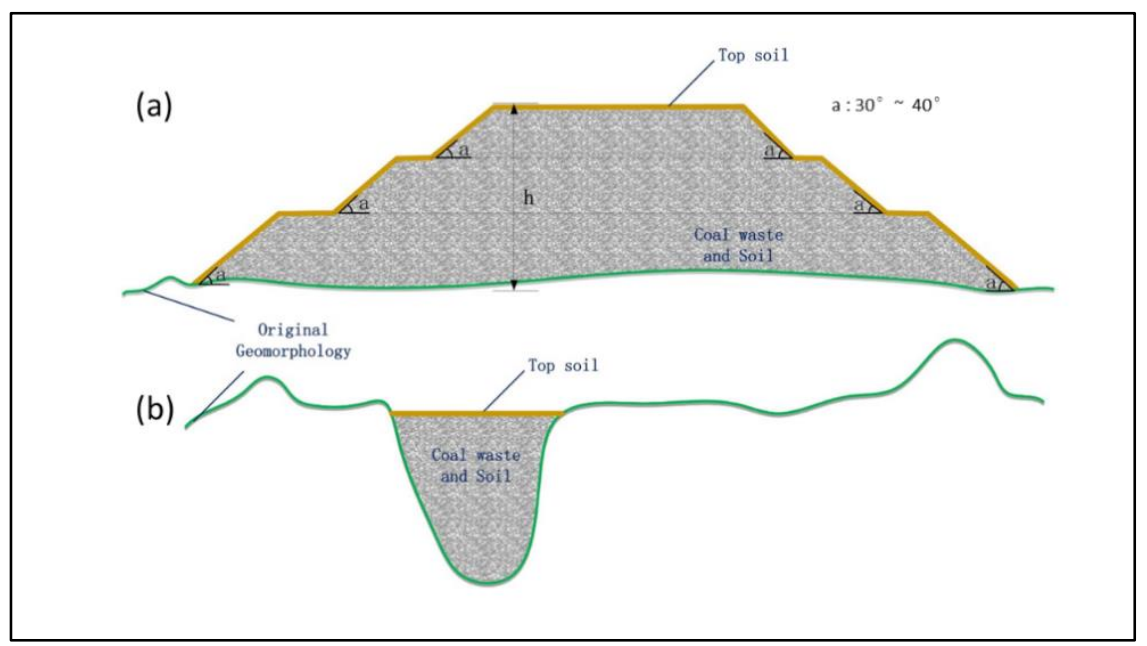

Fig. 1 Waste dump diagram. (a) Multi-stage dump. (b) Gully filled dump.

In view of a series of environmental problems and safety problems caused by surface mining, the land reclamation in mining areas has been carried out in many countries. However, in order to restore the mining eco-system to a stable top community as soon as possible, post-restoration monitoring is still needed. The monitoring of mine restoration mainly includes vegetation restoration, soil quality and soil erosion. Vegetation restoration is the key to the restoration of dump sites. Vegetation restoration can make full use of the function of the soil-plant composite system, improve the local environment and promote a regional ecological balance (Srinivasan Madhusudan et al., 2015), and also significantly improve the soil bulk density, soil moisture content and soil porosity (Wang et al., 2016). Through the calculation of VFC, the vegetation growth status of the dump can be effectively quantified, serving as an important reference for soil erosion. This should give priority to local species with a high survival rate, strong resistance and an ability to improve the physical and chemical properties of the soil. The ideal procedure is to gradually strengthen the composition, structure and level of vegetation, improve the function of the soil and its water conservation and self-renewal ability, and finally to achieve self-balance, establishing a complete and stable ecosystem (Wang et al., 2014). At present, in order to improve the success rate and greening rate of reclamation over a short period of time, most of dump sites adopt artificial management. Although a large area of vegetation coverage can be achieved in a short period of time, it is difficult to achieve a state of self-balance. The monitoring and analysis of vegetation degradation and soil erosion of typical dumps under natural conditions can improve the reclamation method and help dumps to reach ecological balance more quickly. However, there is a lack of research on ecological and environmental monitoring, or disaster monitoring, of the development of dumps under natural conditions (i.e., without artificial management and protection). In addition to this, the quality of the overlying soil layer (Khalil et al., 2014) affects the restoration of vegetation at the dump. The pore structure of the soil affects its hydraulic properties and associated water flow (Wang et al., 2014; Bao et al., 2017). The amount of soil organic carbon (SOC) (Fettweis et al., 2005; Yuan et al., 2018; Zhao et al., 2012), nitrogen (N) (Ye et al., 2017), phosphorus (P) (Liu et al., 2017) and potassium (K) (Zhou et al., 2017) present in the soil are major determining factors and indicators of its fertility and quality, 
which are closely related to vegetation restoration. Heavy metals in a soil not only affect plant development but also threaten the health of the surrounding inhabitants through the food chain (Zhao et al., 2010). Vegetation drought resistance (Zhao et al., 2008) and water and soil conservation (Scorpio et al., 2018) can reduce soil erosion. Nevertheless, the high precipitation intensity (Neugirg et al., 2016) in the rainy season causes the soil moisture to reach saturation, and plants and top soil can easily be carried away due to heavy rainfall (Sahle et al., 2019). Inhomogeneous sedimentation (Tomas et al., 2014), and the gradient (Lü et al., 2013) and aspect (Nyssen et al., 2010) of the dump slope also have an important effect on soil erosion. Erosion gullies and surface collapses caused by soil erosion lead to landslide, debris flow and other disasters, so it is very important to monitor soil quality, vegetation and soil erosion at the dump.

Field measurement is often used in traditional monitoring methods (Jan et al., 2006; Martin Duque et al., 2015; Nyssen, 2006b). With the development of geomechanics, some experts began to use mechanical models to estimate the development of soil erosion (Garry et al., 2006). Considering the natural factors affecting soil erosion, some scholars use the soil erosion equation to conduct quantitative research on soil erosion (Wischmeier and Smith, 1978). Satellite remote sensing (Schroeter and Glaesser, 2011; Obade and Lal, 2013) and UAV remote sensing (Xiao et al., 2017; Ren et al., 2020; Zhao et al., 2020) are also gradually applied to vegetation inversion and soil erosion monitoring in mining areas, it makes multi-frequency and high-spatial-resolution monitoring possible. At present, UAV is mainly used for small-scale topographic surveys for mine monitoring (Kršák et al., 2016) and for large scale geomorphic feature characterization (Chen et al., 2015; Ren et al., 2019). Most studies focus on measuring volume changes at different time scales (Messinger and Silman, 2016; Siebert and Teizer, 2014) and changes in mine land use (Gui et al., 2008), and there is little research carried out on mine dumps. In addition, there is a lack of systematic research on the evolution of a dump, and the associated degradation mechanisms, under the influence of multiple factors. The causes of water erosion (Neugirg et al., 2016) and wind erosion (Yang, 2016) are closely related to topography, vegetation, soil, and slope aspect and gradient. The Geographical Detector (Cao et al., 2013), based on spatial stratified heterogeneity, can be used to analyze the relationship between variables.

By combining UAV remote sensing, satellite remote sensing and field investigation, the main outcomes of this paper are as follows: 1) the acquisition of accurate topography and aetiology (erosion and collapse) data of the dump; 2) a calculation of the vegetation fractional coverage (VFC) of the dump and a sampling of the physical properties of the soil; 3) assessment of the importance of different soil erosion factors, both individually and in combination, using the geographical detector (spatial correlation analysis); 4) according to the main driving factors, some suggestions are put forward to alleviate the soil erosion in the dump. It provides a reference for the land reclamation of open pit mine dump.

\section{Study area}


The experimental plot is located at the Western One site of the Shengli coal field, with geographic coordinates of $115^{\circ} 58^{\prime}-116^{\circ} 2^{\prime} 50^{\prime \prime} \mathrm{E}, 43^{\circ} 59^{\prime}-44^{\circ} 2^{\prime} 15^{\prime \prime} \mathrm{N}$ (Fig. 2), located in Xilinhot, Inner Mongolia Autonomous Region, which is the largest prairie area in China. The mining area has a typical temperate, semi-arid, continental monsoon climate, where the annual average temperature is $0.3{ }^{\circ} \mathrm{C}$ and the average wind speed is above $8.5 \mathrm{~m} / \mathrm{s}$. The total annual precipitation averages 294.9 $\mathrm{mm}$, with more than $70 \%$ occurring from June to August. The average annual effective evaporation is $1811.3 \mathrm{~mm}$, which is more than six times greater than the amount of precipitation. The coal mine has a coal-bearing area of $342 \mathrm{~km}^{2}$, with proven reserves of 15.932 billion tons, most of which are suitable for open-pit mining. There are three main external dumping sites, namely south dump, north dump and side dump. All the three waste dumps had been reclaimed, with a green area of $8.64 \mathrm{~km}^{2}$.

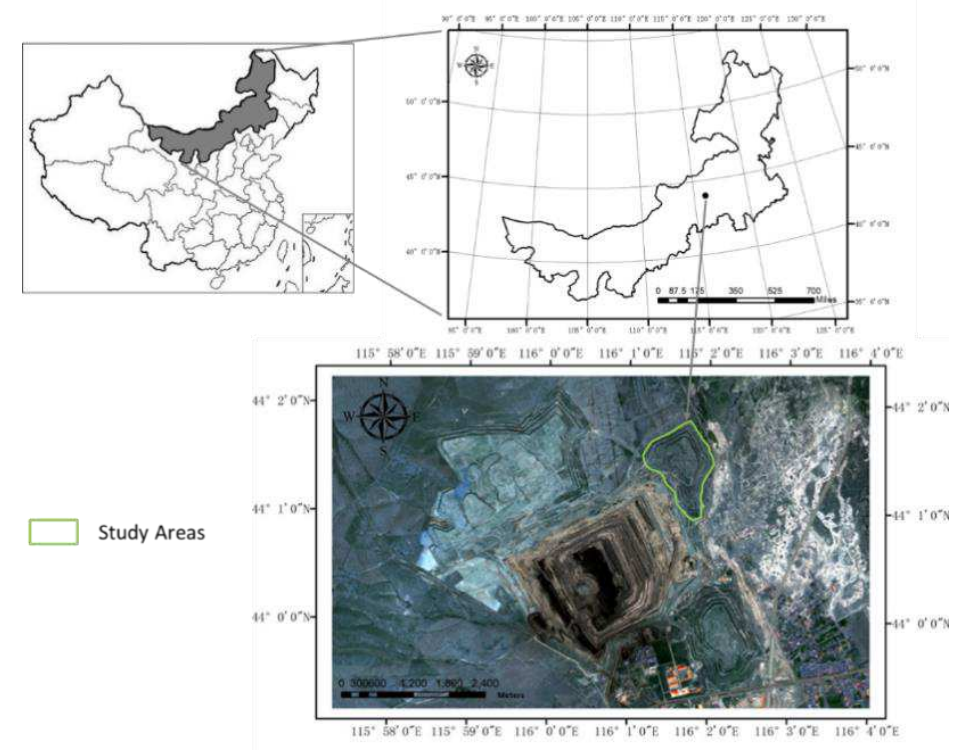

Fig. 2 The study area location.

The specific study area is located in north dump of the Western One site of the Shengli coal mine, with an area of $1.07 \mathrm{~km}^{2}$. The dump is divided into four platforms with an altitude range of $980 \mathrm{~m}-1040 \mathrm{~m}$ and a slope angle of $33^{\circ}$. North dump has been reclaimed since 2006 , with a total land area of $1.01 \mathrm{~km}^{2}$, in which the slope greening area is $0.355 \mathrm{~km}^{2}$, the platform greening area is $0.655 \mathrm{~km}^{2}$, and the green rate is $100 \%$. Since the cessation of artificial conservation in 2013 , the vegetation at the dump site has been degraded, and concentrated precipitation in summer has led to soil erosion, which can easily lead to slope erosion, collapse, debris flow and other disasters under the action of gravity.

\section{Methodology and Materials}

\subsection{Framework}

As a multi-stage dump, north dump is mainly composed of deep rock-soil, pulverized coal and surface soil close to the coal seam, and siltstone, mudstone and gravel of different sizes away from 
160

161

162

163

164

165

166

167

168

169

170

171

172

173

174

175

176

177

178

the stope. The soil is closely packed, with few internal gaps, the permeability coefficient is very small, the seepage storage capacity is very low, and it contains essentially no humus. Without management and protection, dust and soil erosion can easily occur. Therefore, topsoil with a thickness of 30-50 cm has been added to cover the surface. This part of the soil has a high organic matter content and is fully matured. The soil has favorable air permeability, in which the number of seed banks and microorganisms is large, which is conducive to plant growth. After completion of the soil covering and before the arrival of the rainy season, forage grass seeds and shrub seeds with saltalkali resistance, drought resistance, strong adaptability and nitrogen fixation were planted. Artificial maintenance and management was then carried out for 4 years, including watering, sprinkling and irrigation, adding topdressing fertilizer, disease and insect pest control, soil cultivation and planting. Artificial maintenance and management are quite important for vegetation construction (shown in Fig. 3). However, after this was stopped, north dump deformed to different degrees, and its vegetation degenerated, under the influence of wind and rain erosion (Fig. 4). The intense precipitation which occurs during summer has led to soil and water loss, which can in turn easily lead to erosion ditches, collapse, debris flow and other problems on the slope.

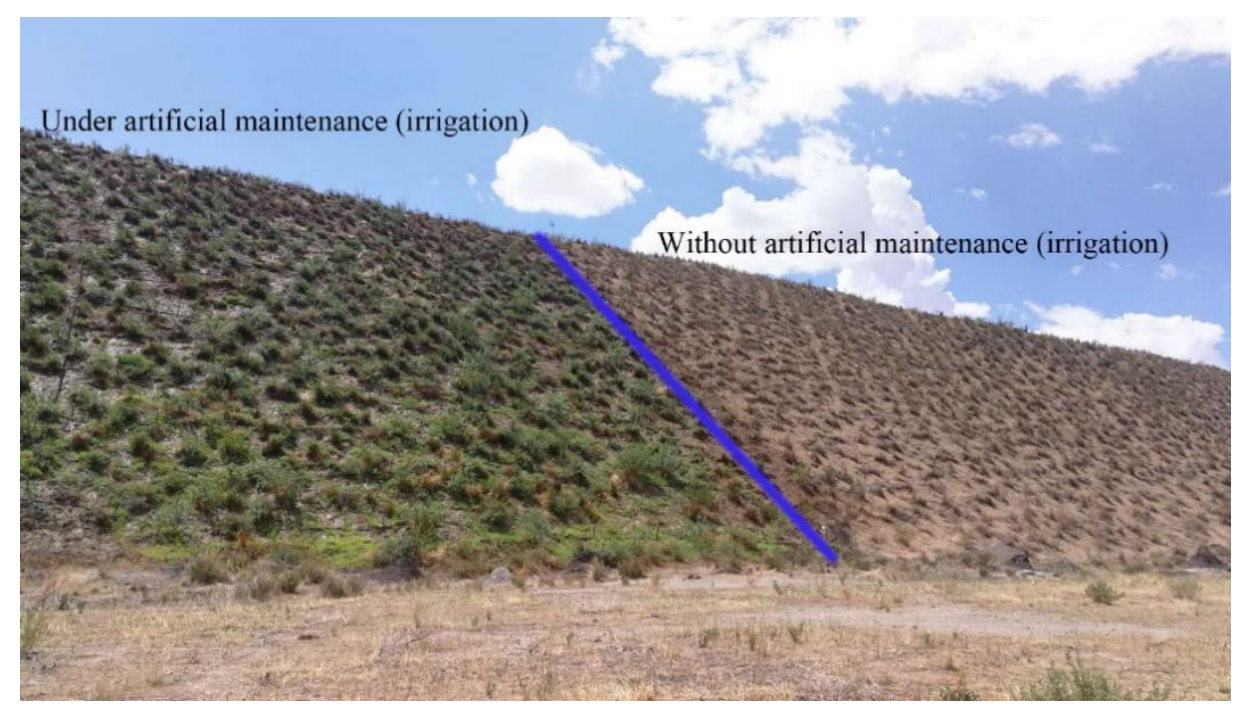

Fig. 3 A comparison of dumps with and without artificial maintenance in the south dumps of Shengli coal field. 


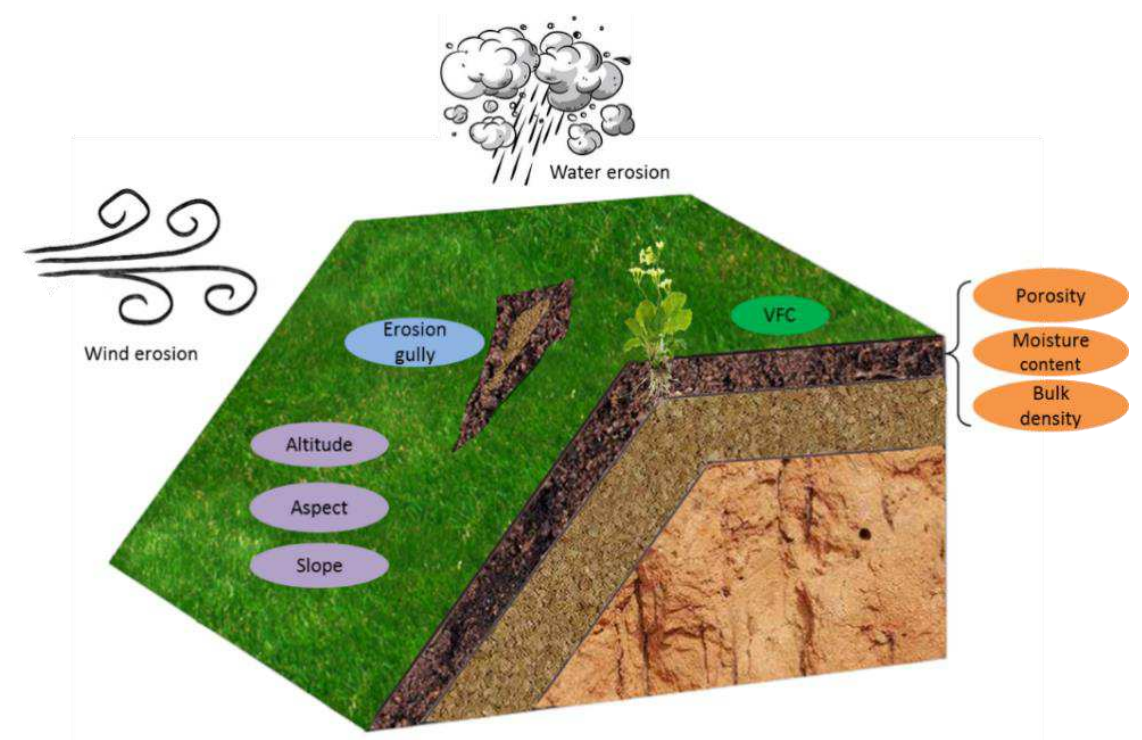

Fig. 4 Potential impact of wind and soil erosion on coal mine dumps under natural conditions.

Wind speed and direction in the study area affects wind erosion on the dump, while intense summer precipitation can cause water erosion. In addition to the vegetation cover and topsoil physical properties themselves, the combined action of these factors will jointly lead to degradation of the dump and soil erosion. Obtaining these parameters quantitatively is particularly important. Jan et al. (2006) conducted interviews to understand the historical development of an erosion gully and calculated the average gully erosion rate through field measurement, Boggs et al. (2000) used GIS and modeling techniques to assess landform evolution, Hancock et al. (2008) quantified rills on an angle of repose slope of undisturbed mine spoil using a terrestrial laser scanner (TLS), and Tarolli and Sofia (2016) analyzed how surface mining affected the environmental landscape using remote sensing technology. However, the interview and modeling methods do not provide complete datasets, while TLS is not suitable for the acquisition of data over a large area, and the visible band of remote sensing is limited by spatial resolution. The research idea of this paper (Fig. 5) is to use a combination of methods to assess the soil erosion and land degradation. The vegetation fractional coverage value of the dump is calculated using the RED and NIR bands of the GF-1 satellite. Obtaining highprecision topographic feature information and the abrasion degree of soil erosion furrows of the dump, in its unmanaged natural state, is done using aerial photogrammetry from a UAV equipped with a visible light camera. The physical properties of the topsoil are obtained by interpolation after field sampling. Finally, by analyzing the topsoil physical properties, VFC, elevation, step slope gradient, slope aspect, and morphological characteristics of erosion gullies in north dump using the Geographical Detector, the main factors leading to erosion can be identified, providing an effective reference for ecological recovery of the dump in the future. 


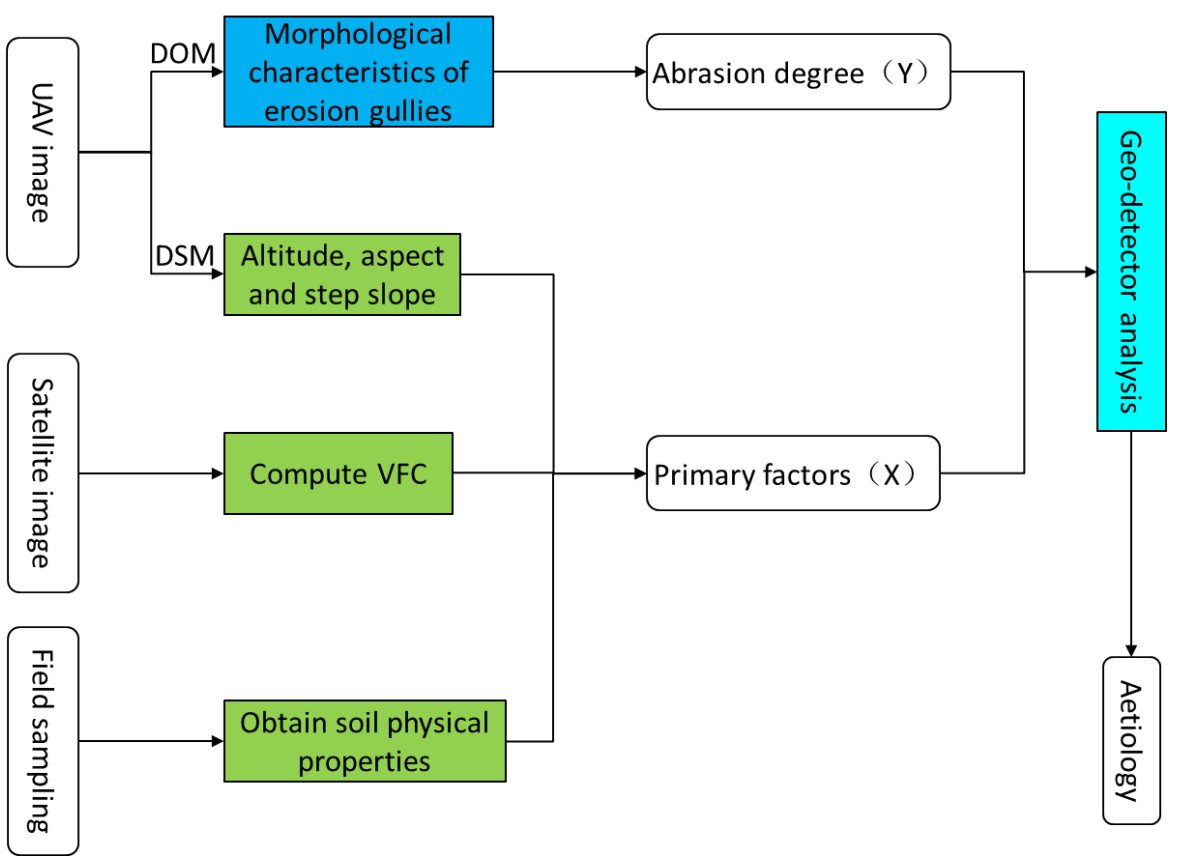

Fig. 5 Methodology flow chart.

\subsection{Soil property}

Soil is the foundation of vegetation restoration in dump lands, and determines the quality of reclamation (Liu et al., 2016a). The physical properties of the soil, such as its moisture content, bulk density, specific gravity, porosity, etc., can influence respiration and the water absorption of plant roots. Soils with deep root systems are characterized by high porosity, high soil infiltration and low soil bulk density (Wang et al, 2018). Nevertheless, the soils of overburden dumps are physically poor, and usually consist of a mixture of coarse-grained particles and rock fragments. In addition, the intensive traffic of heavy machinery used during reclamation can seriously compact soils, further degrading its physical quality. This anthropogenic activity has a significant influence on the soil stability to surface weathering, groundwater or infiltration, gully erosion and slope morphology (Huang et al., 2015).

The physical properties of the topsoil of north dump were obtained by field sampling. Samples from 117 points were collected in May 2017, uniformly spaced along the dump with a step length of $100 \mathrm{~m}$. The sampling points were supplemented at soil erosion locations (Fig. 6) and the sampling depth was $15 \mathrm{~cm}$. Samples at each sampling point were taken using a cutting ring, placed in a sealed bag, fresh weight of soil was measured on site, and sent to the laboratory 4 days later to measure their physical properties, including dry weight, porosity, water content and bulk density. The soil moisture content was determined using a drying method. Fresh weight of soil was measured on site, and dry weight was measured after drying in the laboratory. The soil bulk density and total porosity were determined using a cutting ring method. We pressed the ring knife vertically into the topsoil, and dig the ring knife out of the soil with a shovel and flatten the upper and lower ends. 

brought back to the laboratory for weighing.

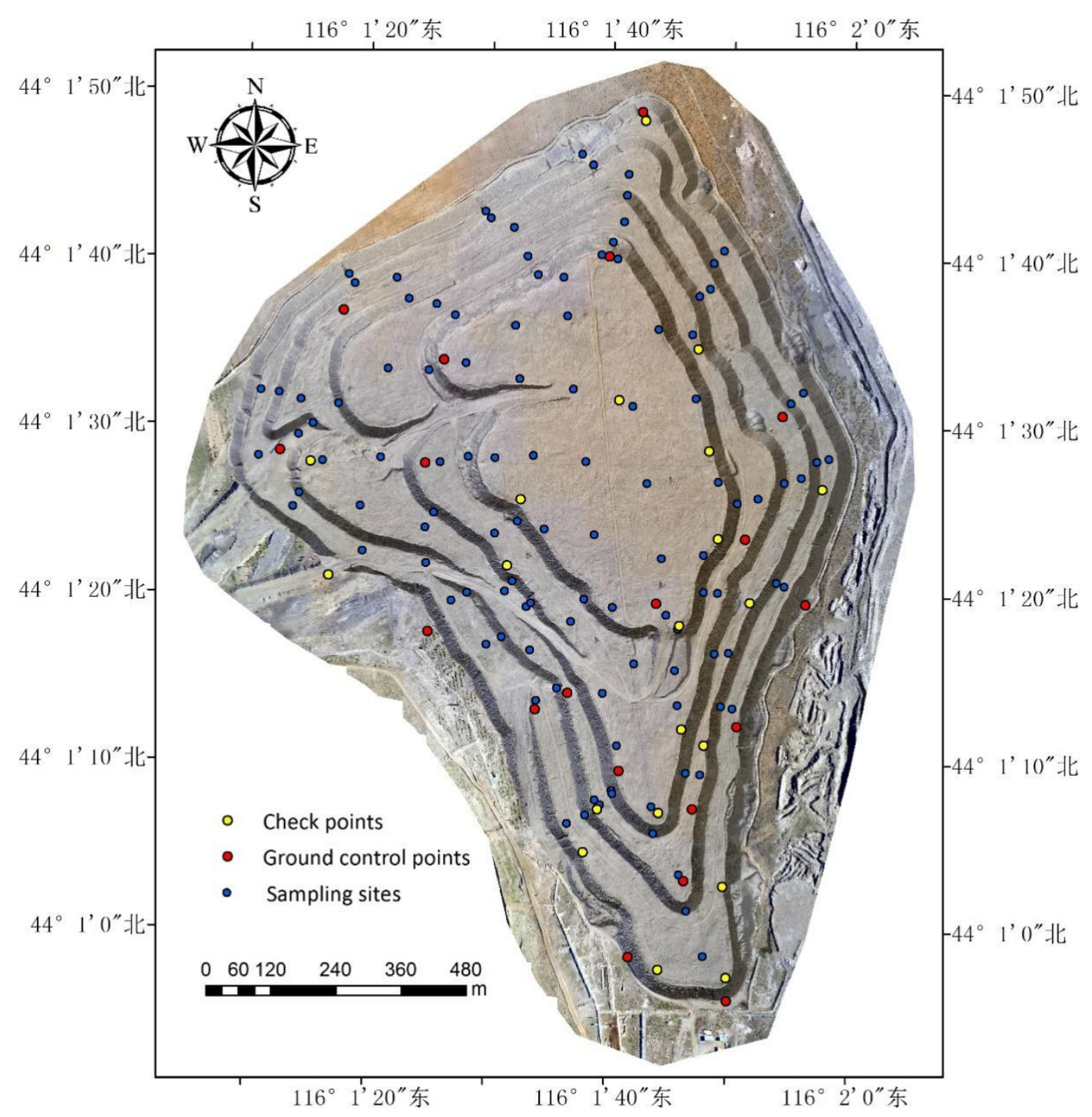

Fig. 6 Sketch map of ground control points, control points and sampling sites.

\subsection{Vegetation fractional coverage}

Vegetation fractional coverage (VFC) is calculated from GF-1 remote sensing satellite images, taken in August 2017. The GF-1 satellite is the first satellite of China's high-resolution Earth observation system, launched from the CZ-2D carrier rocket at 12:13:04 on April 26, 2013. It is characterized by the addition of a multispectral camera with high spatial and temporal resolution (Table 1). It is widely used in the fields of geographical mapping, oceanic and atmospheric meteorological observation, water conservation and forestry resources monitoring, fine management of urban areas 
and transportation, epidemic situation assessment and public health emergency response, and scientific research on the Earth system. Based on the growth cycle of plants and the visibility of satellite images, the multi-spectral image with a spatial resolution of $8 \mathrm{~m}$ obtained by GF-1 on August 11, 2016 was adopted. At this time, the plant growth condition was relatively good and there was relatively little cloud cover. To improve the quality and reduce the effects of terrain and atmospheric noise, the images were preprocessed using geometric correction, radiometric calibration, and atmospheric correction from ENVI 5.2.

Table 1 GF-1 specifications

\begin{tabular}{ll}
\hline Specifications & Details \\
\hline$G F-1$ & Sun synchronous and repeating ground trace \\
Orbit type & $645 \mathrm{~km}$ \\
Orbit altitude & $98.0506^{\circ}$ \\
Orbit inclination & $10: 30$ AM \\
Descending node local & $41 \mathrm{~d}$ \\
time & $2 \mathrm{~m}$ (Panchromatic camera) \\
Regression cycle & $8 \mathrm{~m} \& 16$ m (Multispectral camera) \\
Spatial resolution & $4 \mathrm{~d}$ \\
\hline
\end{tabular}

Vegetation fractional coverage (VFC) is based on the pixel dichotomy model established by Li et al. (2004). The estimation accuracy can reach $85 \%$, but due to the limitation of spectral information, when the vegetation coverage is higher than $85 \%$, the estimated value is obviously lower than the actual value, and the estimated value is no longer increased when it is about $90 \%$. Because the study area is located in arid grassland and vegetation is sparse, where few areas have vegetation coverage of more than $90 \%$. It is very suitable to take this model estimate the vegetation cover of the dump. Firstly, the normalized difference vegetation index (NDVI, denoted NDVI) is calculated from the RED $(R)$ and NIR (NIR) bands of remote sensing images:

$$
N D V I=\frac{N I R-R}{N I R+R}
$$

VFC $(V F C)$ is then defined as a uniform NDVI value: 
$257 \quad V F C=\frac{N D V I-N D V I_{S}}{N D V I_{V}-N D V I_{S}}$,

with the following definitions:

$N D V I_{S}:$ NDVI values of bare soil or areas covered with no vegetation.

$N D V I_{V}$ : NDVI values of pixels completely covered by vegetation.

These quantities can be calculated from:

$N D V I_{S}=\frac{V F C_{\max } \cdot N D V I_{\min }-V F C_{\min } \cdot N D V I_{\max }}{V F C_{\max }-V F C_{\min }}$,

$N D V I_{V}=\frac{\left(1-V F C_{\min }\right) \cdot N D V I_{\max }-\left(1-V F C_{\max }\right) \cdot N D V I_{\min }}{V F C_{\max }-V F C_{\min }}$

We take $V F C_{\max }=1$ and $V F C_{\min }=0$, so equation (2) can be expressed as:

$V F C=\frac{N D V I-N D V I_{\min }}{N D V I_{\max }-N D V I_{\min }}$

where NDVI values with accumulative probability of $5 \%$ and $95 \%$ were taken as $N D V I_{\min }$ and $N D V I_{\max }$ respectively.

VFC values range from 0 to 1 , and the following results are found in this study, through field investigation and comparison with remote sensing images. An area with VFC greater than 0.8 is a high VFC area, and the plants are mainly pinus (Genus), ulmus pumila and armeniaca sibirica trees. Between 0.4 and 0.8 represents a medium VFC area, and the vegetation mainly includes shrubs such as C. korshinskii and hippophae rhamnoides. Lower than 0.4 corresponds to a low VFC area, which is dominated by herbs such as medicago sativa and astragalus adsurgens and bare land.

\subsection{UAV photogrammetry}

Traditional methods for geomorphological measurement use total station instrument (Kršák et al., 2016) or Global Navigation Satellite Systems (GNSS). Although the measurement accuracy is high, the data density is low, making it difficult to use for fine measurements (Aguera-Vega et al., 2017). UAV photogrammetry can make use of the advantages of aerial triangulation to make a complete and comprehensive observation of the area of interest, and has high measurement efficiency and low cost, so it is widely used in topographic mapping of open mining areas.

To ensure the elevation accuracy of the digital surface model (DSM), 39 terrain points (Fig. 6) were measured using CORS (Continuously Operating Reference Stations) with Trimble R8 GNSS receivers. Of these, 19 points were chosen as check points, and the remaining 20 ground control 
points (GCP) served as photogrammetric targets.

The Matrice 100 was chosen as the UAV used in this study. Its fuselage is made of carbon fiber material, making it flexible and light, with a maximum flight duration of $40 \mathrm{~min}$. It can be expanded flexibly and has the possibility to be further developed by the user. The camera used to acquire the images was the Zenmuse X3. The drone took off from the highest platform at a relative flight altitude of $100 \mathrm{~m}$. The longitudinal overlay of the photos was $80 \%$, and the lateral overlay was $60 \%$. The survey took $57 \mathrm{~min}$ and 815 pictures were captured. The processing of the images was performed using the Pix4D mapper software, which allows the reconstruction of a 3D model from the images by applying SfM (Structure from Motion) algorithms. Pix4D mapper is highly automated, with easy one-key manipulation. Users only need to input coordinates of GCPs and identify the location of GCPs in the images, and it requires neither professional knowledge to process data and view the results nor further human processing of the UAV data to automatically generate the digital evaluation model (DEM) and the digital orthophoto map (DOM). Data results can be converted into other formats for other software. The first step is to input them to the Pix4D desktop to carry out image alignment after adjusting for chromatic aberration, noise, and the white balance of the pictures. We obtained the camera position corresponding to each picture, the internal camera orientation parameters, and the sparse point cloud of the terrain, by using feature identification and feature matching. The second step is to import and identify GCPs. The terrain profile, composed of a sparse point cloud, can be seen where the aerotriangulation rays intersect, so that GCPs can be easily identified. In the final step, the dense point cloud, 3D scene reconstruction, post-processing, the DSM and the DOM are produced using a one-key procedure. The terrain of the whole dump can be obtained from the DEM while particular locations on the dump can be extracted from the DOM.

\subsection{Geographical detector}

The geographical detector model was developed for exploring the relationships between spatial patterns of landscapes and the factors which impact them, by Wang et al. (2010). Its principle is that the spatial distributions of two attributes tend to be similar, if there are spatial relationships or interactions between them. The spatial data do not have to be stratified in geospatial terms, although the attributes can be stratified. The similarity between two attributes can be represented by the so-called power of determinant $\left(P_{D, H}\right)$, without requiring many external assumptions or constraints. It is defined as:

$P_{D, H}=1-\frac{\sum_{\mathrm{i}=1}^{m}\left(n_{D, i} \times \sigma_{D, i}^{2}\right)}{n \sigma^{2}}$,

with the following variable definitions:

$P_{D, H}$ : the power of determinant of the $D$ factor to the abrasion degree $(H)$. 
$n$ : the total number of units in the study area.

$n_{D, i}$ : the number of cells in the $i$ th partition in the $D$ factor.

$\sigma:$ total standard deviation of the abrasion degree.

$\sigma_{D, i}:$ standard deviation of the $i$ th partition in the $D$ factor.

The geographical detector model is effective at analyzing the effects of different driving factors on spatial heterogeneity, and it has been applied to research on landscapes (Liang and Yang, 2016), the environment (Zhang and Zhao, 2018) and animal habitats (Liao et al., 2016). Geogdetector was employed in our study to objectively assign weights to different environment factors affecting soil erosion hazards at the dump. As the dependent variable, soil erosion was described by the erosion area. The area of gully erosion was described by the maximum length multiplied by the maximum width, and the area of sheet erosion was identified manually. The independent variables were the step slope gradient, elevation, VFC, degree of porosity, bulk density, soil moisture content and slope aspect for each hazard location. In this way, the main driving factors that affect the amount of soil erosion were assessed. The geographical detector consists of four parts, i.e., the factor detector, interaction detector, risk detector, and ecological detector. We focused on the factor detector and the interaction detector in this study.

\section{Results}

\subsection{Soil property analysis}

The main soil components of the dump are siltstone, mudstone, carbonaceous mudstone and chestnut soil. However, the proportion of chestnut soil is very small, with an average overburden thickness of $30 \mathrm{~cm}$, a sandy soil texture and a humus content between $1.5 \%$ and $3 \%$. Table 2 shows the physical properties of the soil samples. The average bulk density of the topsoil is as high as 1.51 $\mathrm{g} / \mathrm{cm}^{3}$, and the average porosity of the soil is $35.89 \%$. The soil tightness is much higher than that of the soil under natural conditions. The average value of soil moisture content was $3.83 \%$, indicating the topsoil has a poor ability to conserve moisture, therefore it has a low fertility and is not conducive to plant growth, making it susceptible to erosion. The sampling points were interpolated using the Kriging method to obtain the physical properties (Mendes et al., 2019) of the entire dump (Fig. 7), including soil moisture content, porosity and bulk density. The topmost platform is the most heavily compacted, so that it has the smallest porosity, maximum bulk density and minimum water content. 


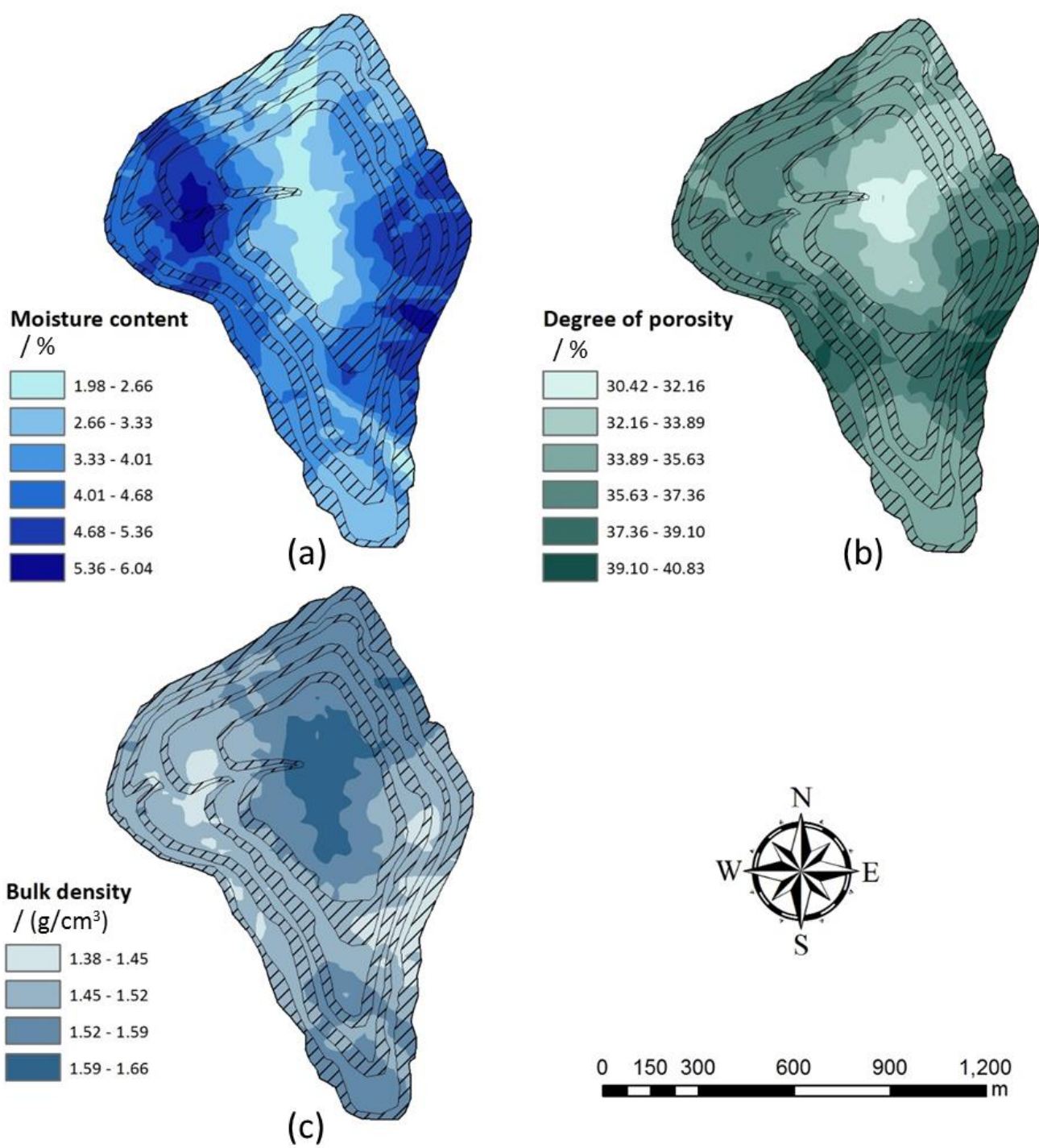

347 Fig. 7 Soil physical properties. (a) Moisture content. (b) Degree of porosity. (c) Bulk density. 348

Table 2 soil physical properties

\begin{tabular}{ccccc}
\hline $\begin{array}{c}\text { Statistical } \\
\text { result }\end{array}$ & Bulk density & Porosity & \multicolumn{2}{c}{ Moisture content/\% } \\
\cline { 3 - 5 } & & & $\begin{array}{c}\text { Original } \\
\text { value }\end{array}$ & $\begin{array}{c}\text { Logarith- } \\
\text { metics }\end{array}$ \\
\hline Maximum & 1.860 & 55.770 & 13.298 & 1.124 \\
Minimum & 1.040 & 21.952 & 0.667 & -0.176 \\
\hline
\end{tabular}




\begin{tabular}{ccccc}
\hline Average & 1.511 & 35.885 & 3.832 & 0.498 \\
Median & 1.520 & 35.943 & 3.019 & 0.480 \\
Standard & & & & \\
deviation & 0.150 & 5.545 & 2.565 & 0.270 \\
Variance & 0.023 & 30.746 & 6.578 & 0.073 \\
\hline
\end{tabular}

The soil porosity of the dump site in the study area is low around and high in the middle, which may be due to the fact that the top platform has been repeatedly rolled by heavy machinery, resulting in soil hardening and topsoil hardening (Liu et al., 2016b). Although dust is reduced to a certain extent, the soil with low porosity reduces the infiltration rate of water, resulting in a large amount of surface water runoff, thus causing soil erosion.

\subsubsection{Moisture content}

The east and west sides of the dump have the highest water content. The high moisture content on the east side is due to the short illumination time and the low evaporation on sunny slopes. The high moisture content in the west is because there is a lane leading to the top on the platform in the west of the dump. After long-term rolling, the platform in the west is sunken, which plays a certain role in water collection. The low moisture content on the south side is due to sunny slopes (Pan et al., 2017). On the north side, the dry and cold monsoon prevailing in spring and winter takes away a large amount of water from the soil surface, so the soil moisture content is low.

\subsubsection{Bulk density}

The distribution of soil bulk density on slope surface is affected by vegetation and topography. The moisture, nutrient and air content in soil also change with the slope position. As water flows through the surface, it moves fine particles from the soil to the bottom of the slope. With the rain erosion, some slope will also occur collapse. The soil surface structure from the upper slope to the lower slope tends to change from compact to loose and porous (Lü et al., 2018).

\section{2 $\mathrm{VFC}$}

Vegetation coverage is affected by the physical properties of the topsoil(Huang et al., 2015), plant species(Liu et al., 2016b) and local climate(Brown et al., 1997), and there is significant variation in its spatial distribution. The north dump covered 483,580 $\mathrm{m}^{2}$ of low vegetation, $453,704 \mathrm{~m}^{2}$ of medium vegetation and $120188 \mathrm{~m}^{2}$ of high vegetation on September 1, 2017. As can be seen from 
Fig. 8a, the high VFC areas are mainly distributed on the slope surface, which has not been compacted by heavy transport equipment and is more conducive to water infiltration and plant root growth (Qi, 2017). In the high VFC area of the platform in the south of the dump, because of intensive planting during reclamation, the tree cluster distribution makes it more stable and not so vulnerable to degradation. In different slope aspect, VFC of north slope and east slope was higher than that of south slope and west slope. It indicates that the growth of vegetation is closely related to the slope direction (Frankard et al., 2000). The north slope and the east slope are shady slopes with short light time, weak plant transpiration and little water evaporation, while the south slope and the west slope are sunny slopes with long light time, strong plant transpiration and much water evaporation, which is difficult for vegetation restoration.

\subsection{Geomorphology and gully erosion}

We utilized a SfM algorithm to process the aerial photos to acquire the geomorphology and gully erosion of the dump. The slope aspect (Fig. 8b) and gradient (Fig. 8c) were then obtained from the DSM. The slope gradients of each platform are approximately equal, at about 33 degrees, however, the step slope aspects are more variable (Fig. 9). In the north, northwest, northeast, east and southeast directions, the step slope gradients are about 16 degrees, but in the west, southwest and south directions, the step slope gradient is significantly shallower, even reaching as low as approximately 6 degrees. The greater the step slope gradient is, the more vulnerable the surface is to cause Rock fragment movement (Nyssen et al., 2006a) and wind-water erosion (Zhang et al., 2019). 

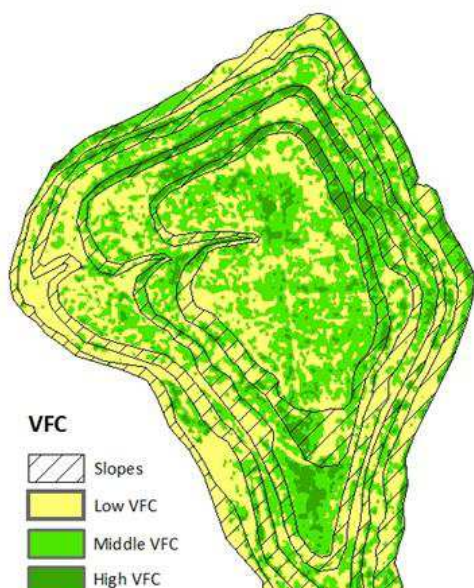

(a)
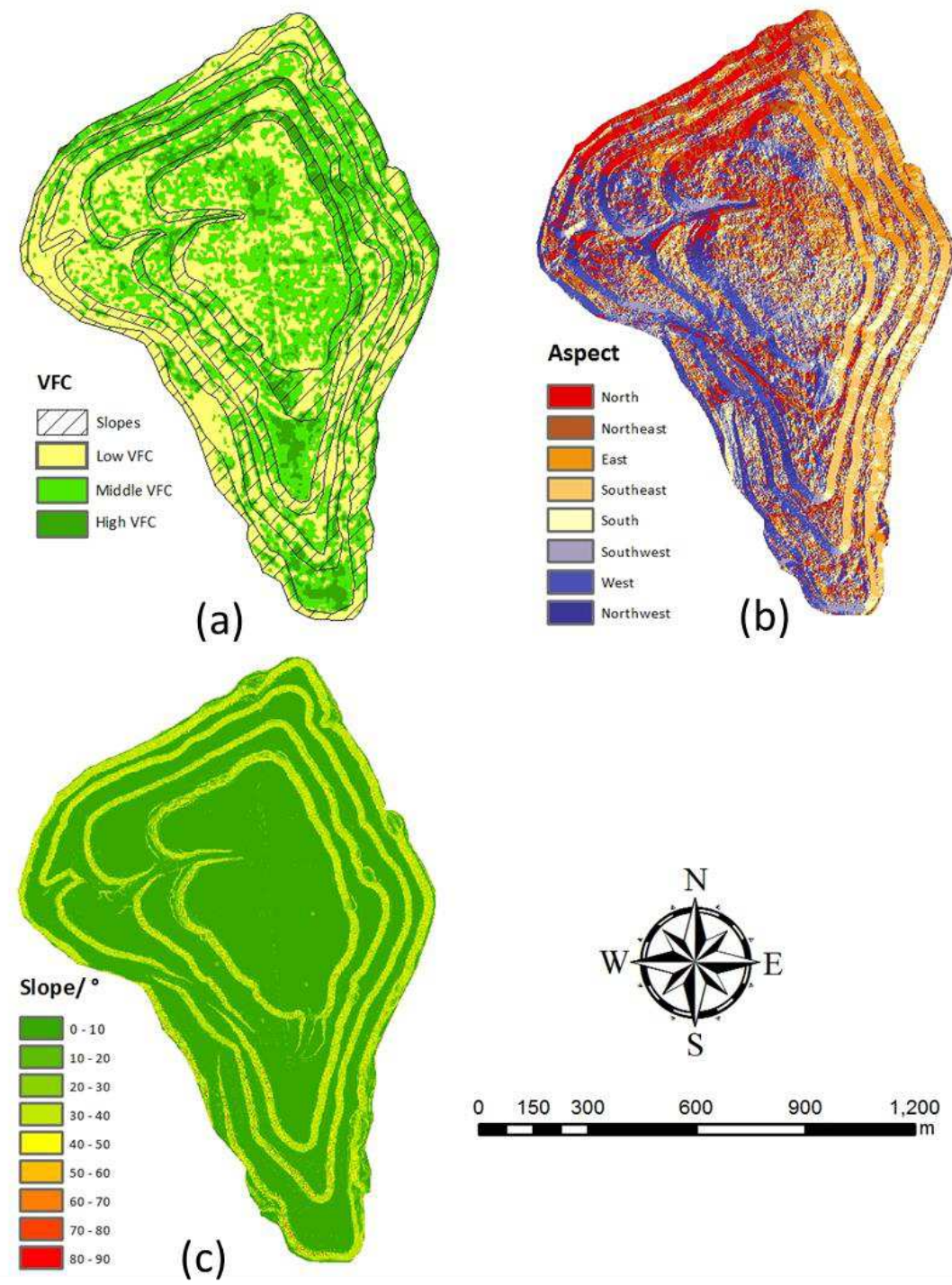

Fig. 8 VFC, Slope aspect and gradient. (a)VFC. (b) Aspect. (c) Gradient. 


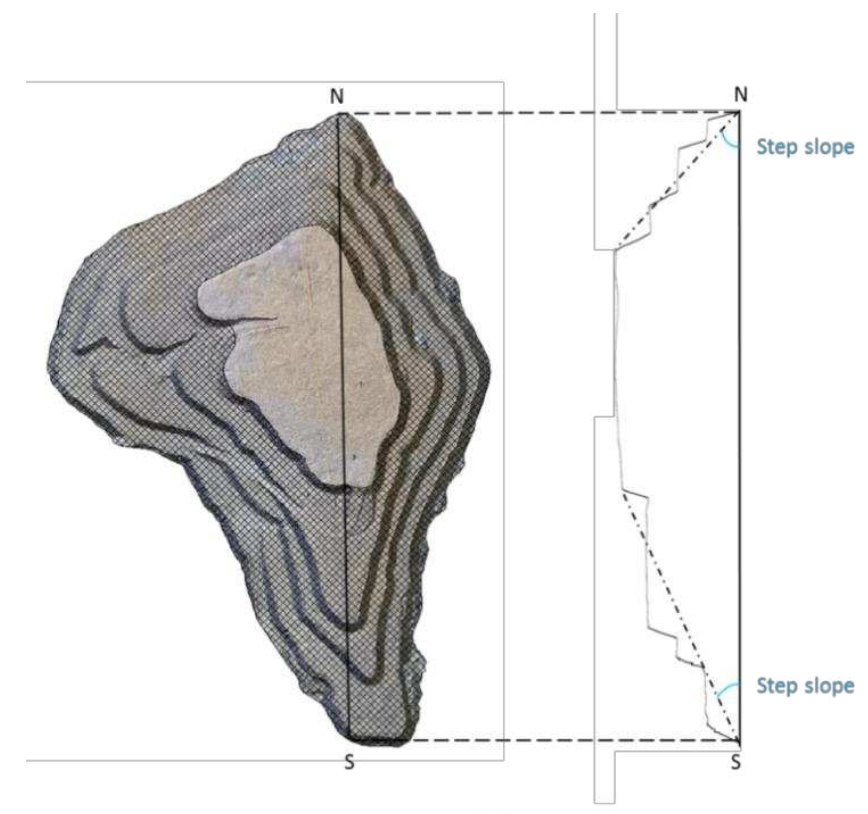

(a)

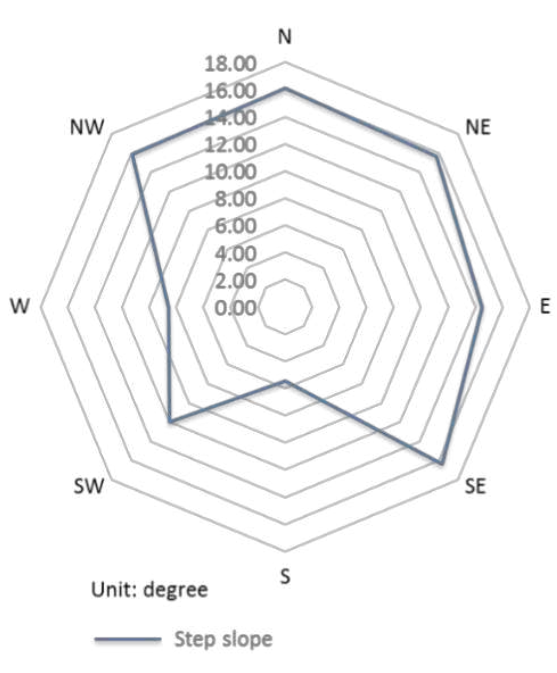

(b)

Fig. 9 Step slope. (a) The elevation profile from the DSM is shown on the right, with its location shown on the map on the left. (b) Radar chart of the step slope gradient.

The resolution of the DOM was $6 \mathrm{~cm}$. Fig. 10 shows the distribution of erosion gullies and collapsed areas. All the geological hazards are located in slope areas. The heavy mechanical equipment used in the dump compacts the dump platform, making it less susceptible to infiltration of heavy rain. However, on the slopes of the dump, loose rocks and soils, poor stability, and low water content make it vulnerable to water-wind erosion (Kainthola et al., 2011). The erosion gullies radar chart (Fig. 11) shows the erosion extent on four platforms in different directions. It can be found in combination with Table 3, the region with the most serious soil erosion was located west to northwest of the dump, where five collapse areas were concentrated, totaling $7399.57 \mathrm{~m}^{2}$, and accounting for $53.72 \%$ of the total erosion area. Erosion gullies were mainly distributed on the west side of the dump, accounting for $50 \%$ of the total erosion gullies. There were 13 erosion gullies to the west $\left(247.5^{\circ}\right.$ to $\left.292.5^{\circ}\right), 16$ erosion gullies to the northwest $\left(292.5^{\circ}\right.$ to $\left.337.5^{\circ}\right)$, and 20 erosion gullies to the southwest $\left(202.5^{\circ}\right.$ to $\left.247.5^{\circ}\right)$. The number of erosion gullies on the east side (E, NE, SE) was smaller, accounting for $28.26 \%$ of the total. The slope aspect with more severe erosion is in line with the prevailing local wind direction (Nyssen et al., 2010). The soil erosion of the fourth platform slope(crest) is the most serious, while the soil erosion of the first and second layers is lighter than that of the other two, as also shown by Cha et al. (2000). This indicates that wind erosion is a significant cause of these hazards. 


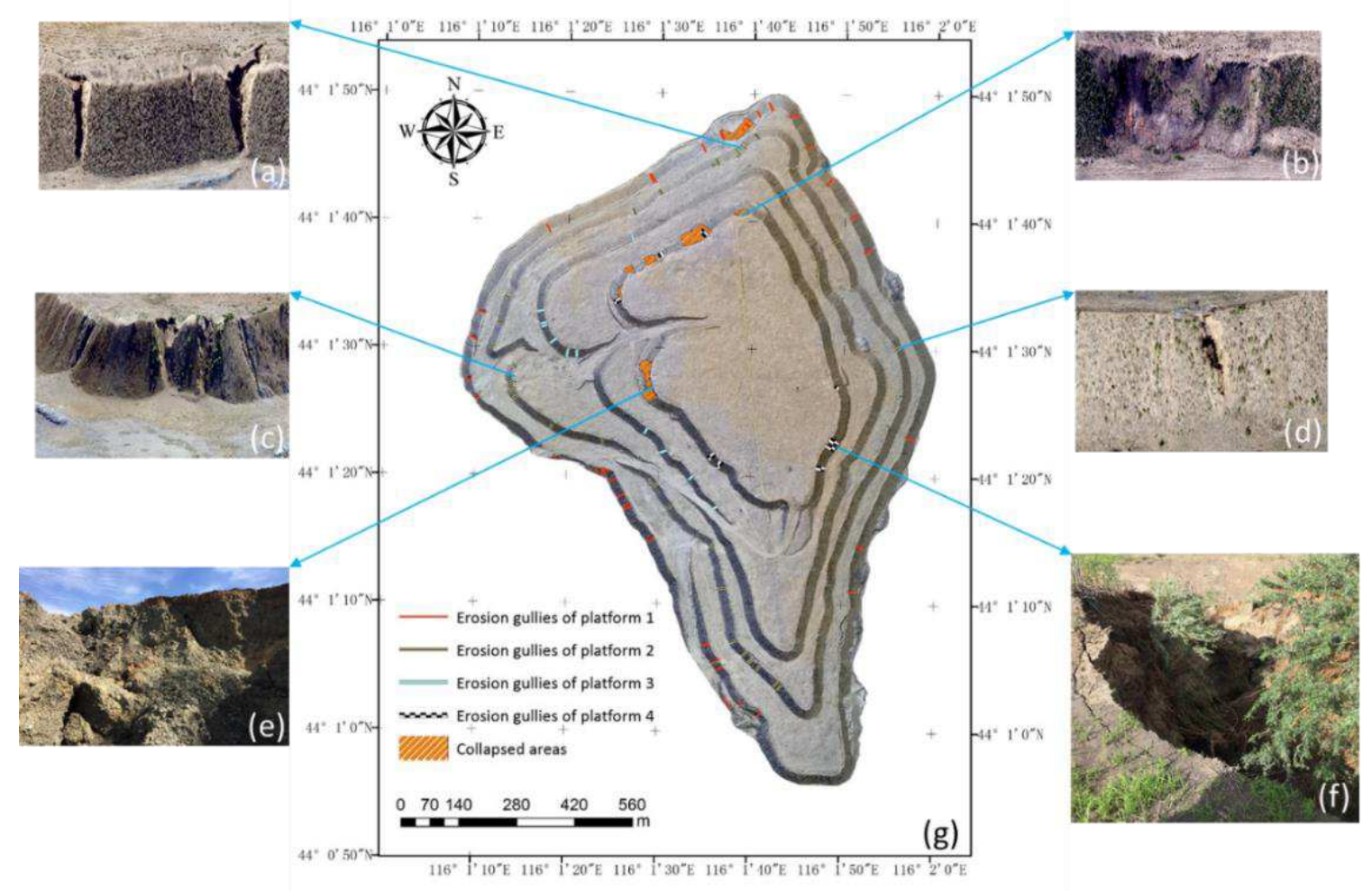

Fig. 10 Geologic hazards at north dump. (a-d) Hazards shown in 3D models. (e-f) Photos taken in the field. (g) Distribution of hazards.

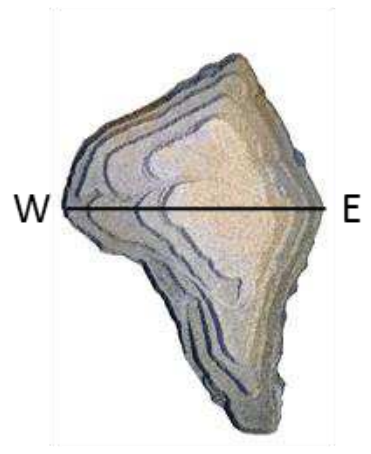

(a)

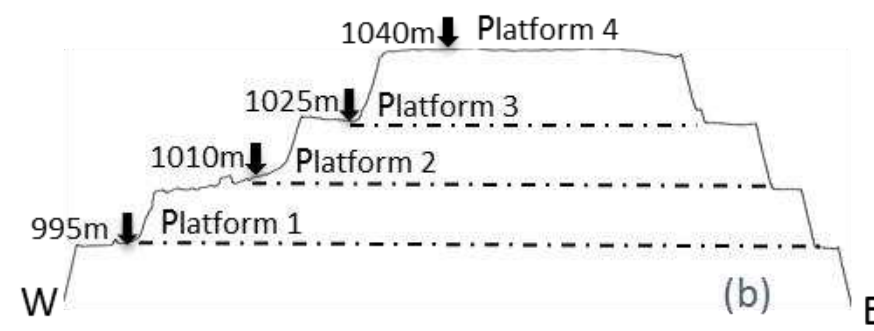

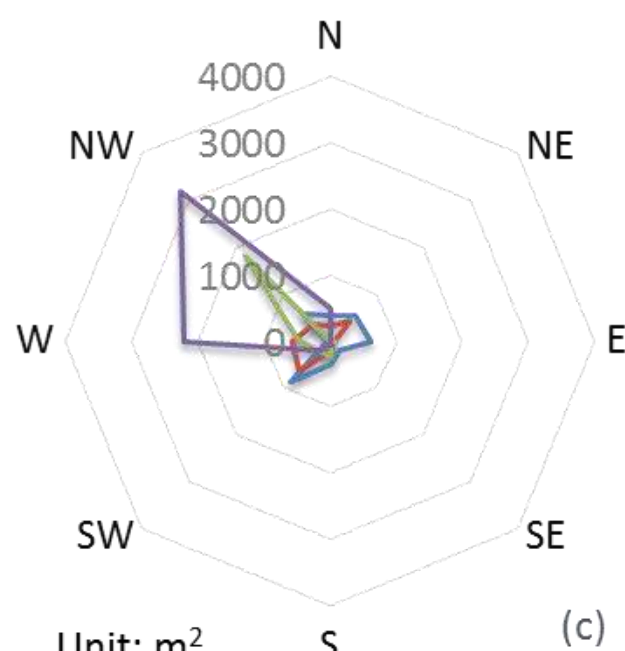

(c)
Unit: $\mathrm{m}^{2} \quad \mathrm{~S}$

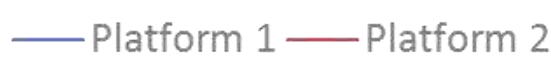

E Platform 3 - Platform 4

424 Fig. 11 Erosion gullies radar chart. (a) Section line. (b) Transverse section. (c) Radar chart of erosion extent of each platform: the distance from the center represents the erosion extent. 
Table 3 Distribution of soil erosion

\begin{tabular}{ccccc}
\hline Aspect & $\begin{array}{c}\text { Erosion } \\
\text { gullies }\end{array}$ & $\begin{array}{c}\text { Cumulative } \\
\text { gullies ratio }\end{array}$ & $\begin{array}{c}\text { Erosion } \\
\text { areas }\end{array}$ & $\begin{array}{c}\text { Cumulative } \\
\text { area ratio }\end{array}$ \\
\hline N & 10 & $10.87 \%$ & 1108.72 & $8.79 \%$ \\
NE & 13 & $25.00 \%$ & 948.12 & $16.31 \%$ \\
E & 8 & $33.70 \%$ & 747.39 & $22.23 \%$ \\
SE & 5 & $39.13 \%$ & 272.57 & $24.39 \%$ \\
S & 10 & $50.00 \%$ & 827.58 & $30.95 \%$ \\
SW & 20 & $71.74 \%$ & 1933.28 & $46.28 \%$ \\
W & 10 & $82.61 \%$ & 827.58 & $52.84 \%$ \\
NW & 16 & $100.00 \%$ & 5948.07 & $100.00 \%$ \\
\hline
\end{tabular}

430

431

\subsection{Analysis of dump hazards using geographical detector}

\subsubsection{Factor detector}

The factor detector reveals the impact of a single driving factor on the degree of soil erosion. The power of determinant $\left(P_{D, H}\right)$ of each factor is shown in Fig. 12. This shows that the most important contributing factors are elevation (0.127), slope aspect (0.107), and VFC (0.094), followed by step slope gradient $(0.051)$, degree of porosity $(0.044)$, soil moisture content $(0.043)$, and bulk density (0.028). The larger wind force at the top of the dump accelerates the development of erosion gullies into collapse areas. The collapse areas are mainly concentrated on the slope of the fourth platform, indicating that the higher the elevation of an area is, the more vulnerable it is to soil erosion(Zhang et al., 2012). The slope aspect is related to wind direction. The prevailing westerly wind in spring and winter means that erosion gullies are mainly distributed on the west side of the dump. For regions without soil erosion, vegetation can play a role as a wind break and in sand fixation, thus preventing soil erosion. For regions with soil erosion, vegetation can effectively inhibit the development of erosion gullies and prevent the combination of adjacent collapse areas. Gentle topography helps reduce soil erosion, especially on windward slopes, where a smaller gradient slows 
the acceleration of upwind airflow and gravity subsidence of the topsoil. A surface soil with large porosity is conducive to plant growth and the infiltration of water, thereby reducing water erosion and inhibiting the further development of fissures. The climate in the experimental area is dry. The higher initial soil moisture content is conducive to a stable soil aggregate structure, enhanced soil permeability, and reduced soil disintegration rate, making the soil less susceptible to erosion (Andrea et al., 1997). The power of determinant $P_{D, H}$ of bulk density is small, indicating that bulk density does not have a large direct impact on soil erosion in the dump.

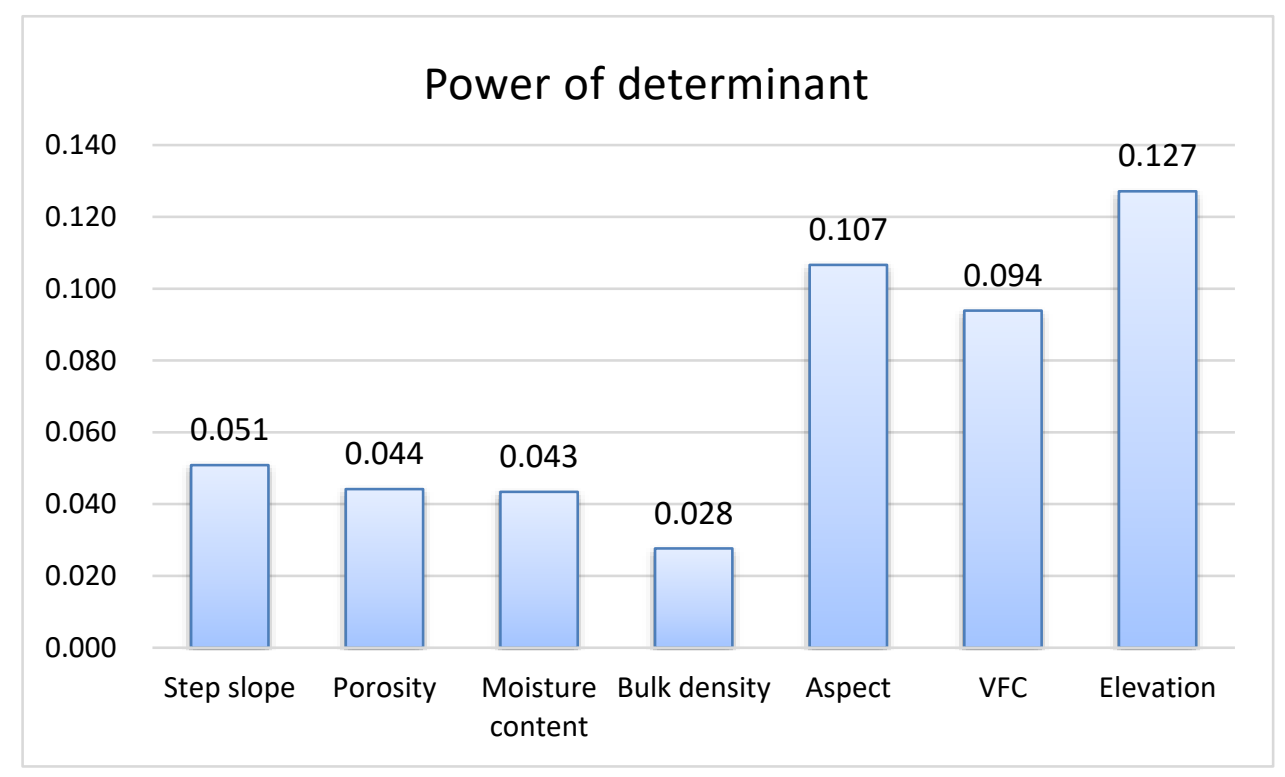

Fig. 12 The influences of different driving factors on the degree of erosion.

\subsubsection{Interaction detector}

Soil erosion on the slope of the dump is the result of the joint action of many environmental factors. In a real environment, the distribution and change of soil erosion cannot be affected by only a single factor or a single natural cause (Xiao et al., 2018). In order to establish whether any two environment factors influence the degree of soil erosion independently, or interact with each other, the interaction detector is applied. The interactive influence between each pair of driving factors is categorized as follows:

Weaken and nonlinear: $P_{D, H}(x \cap y)<\operatorname{Min}\left(P_{D, H}(x), P_{D, H}(y)\right)$

Weaken and univariate: $\operatorname{Min}\left(P_{D, H}(x), P_{D, H}(y)\right)<P_{D, H}(x \cap y)<\operatorname{Max}\left(P_{D, H}(x), P_{D, H}(y)\right)$

Enhance and bivariate: $P_{D, H}(x \cap y)>\operatorname{Max}\left(P_{D, H}(x), P_{D, H}(y)\right)$

Independent: $P_{D, H}(x \cap y)=P_{D, H}(x)+P_{D, H}(y)$

Enhance and nonlinear: $P_{D, H}(x \cap y)>P_{D, H}(x)+P_{D, H}(y)$.

This study found that the interaction detectors for abrasion degree can be divided into two types: enhance and bivariate, and enhance and nonlinear. Though the power of determinant of each pair of 


\begin{tabular}{|c|c|c|c|c|c|c|c|}
\hline & $\begin{array}{l}\text { Step slope } \\
\text { gradient }\end{array}$ & Porosity & Moisture & $\begin{array}{c}\text { Bulk } \\
\text { density }\end{array}$ & $\begin{array}{l}\text { Slope } \\
\text { aspect }\end{array}$ & VFC & Elevation \\
\hline Step slope & 0.051 & & & & & & \\
\hline Porosity & 0.202 & 0.044 & & & & & \\
\hline Moisture & 0.228 & 0.331 & 0.043 & & & & \\
\hline Bulk density & 0.170 & 0.481 & 0.086 & 0.028 & & & \\
\hline Slope aspect & 0.116 & 0.243 & 0.395 & 0.328 & 0.107 & & \\
\hline VFC & 0.443 & 0.650 & 0.367 & 0.399 & 0.487 & 0.094 & \\
\hline Elevation & 0.194 & 0.214 & 0.247 & 0.206 & 0.248 & 0.427 & 0.127 \\
\hline
\end{tabular}

driving factors was bigger than that of each individual driving factor, there were significant differences in the interaction strength of different factors (Table 4). The interactive effects of the step slope gradient and elevation, soil moisture content and bulk density, and slope aspect and elevation were greater than the maximum of their separate effects. However, the interactive effects of other pairs were greater than the sum of the effects of the corresponding factors individually, indicating a strong synergistic effect between the two factors. The interactive influence power of VFC with other factors is higher than 0.36 , indicating that VFC can significantly enhance the impact of various environmental factors on abrasion degree. VFC can be used as an auxiliary indicator factor for the monitoring of the aetiology of erosion and degradation (Tong et al., 2014). In addition, driving factor pairs with strong synergistic effects also include: porosity and moisture content, porosity and bulk density, slope aspect and moisture content, and slope aspect and bulk density. The physical properties of the soil are intrinsically related, and the synergistic effect of slope aspect, moisture content and bulk density is mainly reflected in the change of these physical properties caused by wind erosion.

Table 4 Results of the interaction detector

\footnotetext{
* Footnote: values in bold are stronger than other interactions.
}

\section{Discussions}

\subsection{Implications}

Dumps are inevitable troubles that were formed by open pit mining. Through the analysis in section 4.4, it is concluded that elevation, VFC, and aspect are the main driving factor affecting soil erosion. Soil property and aspect affect the distribution of VFC. VFC, elevation and aspect have combined effects on soil erosion. Slope stability management (Sotiris et al., 2018) and soil erosion (Marchi et al., 2018) are worldwide problems. The temporal and spatial evolution of soil erosion was analyzed by remote sensing (Shivesh Kishore et al., 2016) and model (Wischmeier and Smith, 
1978; Rodriguez Caballero, 2015). Soil erosion is usually controlled by changing land use patterns(Nearing et al., 2005) and geomorphic reclamation(Martin et al., 2015). As it was mainly caused by wind erosion and water erosion, the following three suggestions are put forward according to the characteristics of this area:

(1) Given the serious soil erosion on the windward slope in the west, we suggest reducing the ladder slope gradient to the northwest. The slope would then better reflect the natural landform before its disturbance by human influence, leading to a reduction in wind erosion.

(2) VFC is not only the main factor affecting soil erosion but also an auxiliary indicator for monitoring soil erosion. Increasing VFC is important for the prevention and treatment of land degradation at dump sites. We can introduce dominant species and appropriately increase the density and diversity of vegetation communities. At the same time, sand barriers and biological arpeggios could be adopted to enhance the stability of vegetation community.

(3) Strong wind erosion leads to coarser soil surface particles and a great loss of nutrients. Compaction by large machinery reduces soil porosity and increases bulk density, which is not conducive to plant growth. However, plant roots can reach deep into the soil, promote the agglomeration of micro-aggregates with small particle size, reduce soil bulk density and increase soil porosity, forming a positive feedback loop. Therefore, shrubs and herbaceous pioneer plants with strong adaptability and good survival rates should be widely planted in the early stage of reclamation, so as to provide wind protection, fix the soil and improve the soil structure.

The site-specific suggestions put forward in this paper are applicable to the whole grassland area of Eastern Inner Mongolia. The grassland area of Eastern Inner Mongolia is more than 380,000 $\mathrm{km}^{2}$. More than 40 mining areas are scattered in the grasslands of eastern Inner Mongolia. The total coal resources are 249 billion tons, and the annual mining volume is $150-300$ million tons. The total area of the dump is more than $14,460 \mathrm{~km}^{2}$.

\subsection{Limitation of the method and future work}

In this paper, a method of soil erosion monitoring based on multi-source data and combined with geographical detector can effectively identify the main factors causing soil erosion, but there are still some scientific problems to be solved. On the one hand, the UAV platform can be equipped with multi-spectrum or hyper-spectrum in the future to obtain more spectral information for constructing vegetation parameters. Soil information can be obtained by inverting vegetation parameters, and soil erosion warning can be carried out. On the other hand, using UAV loaded RTK (Real - time Kinematic) can greatly reduce the time of data acquisition, so as to construct a more rapid and efficient monitoring method.

In addition, this thesis only proposes to alleviate wind erosion in the dump by reducing windward slope, but the appropriate gradient is not discussed in depth. In fact, as far back as 1969 geomorphic design approach has been used in landscape planning (McHarg, 1969). At present, the ge- 
omorphic remolding of open-pit mines in the United States and Australia is mainly based on geomorphic design approach. Common software includes GeoWEPP (Hao et al., 2015), GeoFluv (Hancock et al., 2019), and so on. Because of the high cost of land acquisition in China, mining companies will reduce the land acquisition area as much as possible. How to construct the terrain resistant to wind and water erosion is an important direction of mine restoration in the future.

The combined methodology that integrating satellite remote sensing imagery for vegetation monitoring, UAVS platform for accurate terrain and soil erosion investigation, and field sampling for soil property analysis, could fill the gap of different method, that satisfied the demand of coal mine dumps land reclamation monitoring, investigation, assessment.

\section{Conclusions}

This paper investigates an outer dump at which artificial management has been stopped, as an example to explore the soil erosion after 5 years of evolution of natural processes, and to determine the main factors influencing the degree of soil erosion. The main conclusions are as follows:

1) At a height of $100 \mathrm{~m}$, UAV pictures combined with a SfM algorithm can be used to accurately and quickly obtain a 3D model of the dump with a total height of $60 \mathrm{~m}$. The accuracy is sufficient to position and identify the soil erosion area.

2) The step slope gradient of the coal mine dumps is significantly steeper than the natural landform, which makes the windward slope vulnerable to wind erosion. It is suggested that the windward slope be designed to imitate the natural landform, for example by reducing its gradient.

3) Vegetation coverage is the main factor affecting soil erosion. Measures such as sand barriers and biological basketry should be applied at the slope to reduce and restrain gully erosion and planar erosion. Pioneer plants that can improve soil structure should be widely planted on the platform at the early stage of reclamation, so as to facilitate water infiltration and enhance the diversity and stability of vegetation communities during the natural recovery period.

4) The combined methodology that integrating satellite remote sensing imagery for vegetation monitoring, UAVS platform for accurate terrain and soil erosion investigation, and field sampling for soil property analysis, could fill the gap of different method, that satisfied the demand of coal mine dumps land reclamation monitoring, investigation, assessment.

\section{Conflict of interest}

The authors have declared no conflict of interest.

\section{Acknowledgements}

This work is supported by the National Key R \& D Program of China (Grant No. 2016YFC0501103).

\section{References}


Aguera-Vega, F., Carvajal-Ramirez F., Martinez-Carricondo P., 2017. Assessment of photogrammetric mapping accuracy based on variation ground control points number using unmanned aerial vehicle. Measurement 98, 221-227. https://doi.org/10.1016/j.measurement.2016.12.002.

Andrea, R., Katharina, H., Heiko, D., 1997. Effect of antecedent soil water content and rainfall regime on microrelief changes. Soil Technology 69-81. https://doi.org/10.1016/09333630(95)00040-2.

Bao, N.M., Wu, L.X., Ye, B.Y., Yang, K., Zhou, W., 2017. Assessing soil organic matter of reclaimed soil from a large surface coal mine using a field spectroradiometer in laboratory. Geoderma 288, 47-55. https://doi.org/ 10.1016/j.geoderma.2016.10.033.

Boggs, G. S., Evans, K. G., Devonport, C. C., Moliere, D.R., Saynor, M.J., 2000. Assessing catchment-wide mining-related impacts on sediment movement in the Swift Creek catchment, Northern Territory, Australia, using GIS and landform-evolution modelling techniques. Journal of Environmental Management 59, 321-334. https://doi.org/10.1006/jema.2000.0371.

Brown, J.H., Valone, T.J., Curtin, C.G., 1997. Reorganization of an arid ecosystem in response to recent climate change. Proc. Natl. Acad. Sci. USA 94, 9729-9733. https://doi.org/10.1073/pnas.94.18.9729

Cao, F., Ge, Y., Wang, J.F., 2013. Optimal discretization for geographical detectors-base d risk assessment. GIScience \& Remote Sensing 50,78-92. https://doi.org/10.1080/15481603. $\underline{2013.778562 .}$.

Cha, X., Tang, K.L., 2000. Study on comprehensive control model of small watershed e co-environment in water and wind crisscrossed erosion zone (in Chinese). J Nat Resour 20 00,15:97-100. https://doi.org/10.11849/zrzyxb.2000.01.017.

Chen, J., Li K., Chang K., Sofia, G., Tarolli, P., 2015. Open-pit mining geomorphic feature characteri-zation. International Journal of Applied Earth Observation and Geoinformation 42, 76-86. https://doi.org/10.1016/j.jag.2015.05.001.

China Statistical Publishing House, 2017. National bureau of statistics. Statistical yearbook of China, Beijing.

Fettweis, U., Bens, O., Huttl, R.F., 2005. Accumulation and properties of soil organic carbon at reclaimed sites in the Lusatian lignite mining district afforested with Pinus sp.. Geoderma 129, 8191. https://doi.org/10.1016/j.geoderma.2004.12.034.

Frankard, P., 2000. Aperçu de la flore et de la végétation des terrils de la région liégeoise. Bulletin de la Société Royale des Sciences de Liège 69, 265-287. 
Gui, D.Z., Li, G., Lin, Z.J., Zhang, C.C., 2008. Research on mine subsidence control and landscape planning based on unmanned aerial vehicle remote sensing. Science of Surveying and Mapping 33, 46+105-106. https://doi.org/10.3771/j.issn.1009-2307.2008.06.036

Guo, S.C., Tang, A., Li, X.S., Bian, Z.F., Hou, H.P., Ni, H., 2018 Measurement of land damage based on active and passive remote sensing in Wuhai mining area. Journal of Ecology and Rural Environment 34, 678-685. https://doi.org/10.11934/j.issn.1673-4831.2018.08.002.

Hancock, G. R., Crawter, D., Fityus, S. G., Chandler, J., Wells, T., 2008. The measurement and modelling of rill erosion at angle of repose slopes in mine spoil. Earth Surface Processes and Landforms 33,1006-1020. https://doi.org/10.1002/esp.1585.

Hancock, G. R., Martin Duque, J. F., Willgoose, G. R., 2019. Geomorphic design and modelling at catchment scale for best mine rehabilitation - The Drayton mine example (New South Wales, Australia). Environmental Modelling \& Software 114, 140-151. https://doi.org/10.1016/j.envsoft.2018.12.003

Hao, Y., Yu, R., Hao, R., 2015. Research development on geo-spatial interface for water erosion prediction project.Advance in Science and Technology of Water Resources 35(03),99-105.

Huang, L., Zhang, P., Hu, Y.G., Zhao, Y., 2015. Vegetation succession and soil infiltration characteristics under different aged refuse dumps at the Heidaigou opencast coal mine. Global Ecology and Conservation 4, 255-263. http://dx.doi.org/10.1016/j.gecco.2015.07.006

Huang, Y.F., Zhang, S.W., Zhang, L.P., Zhang, H.Y., Li, Z., 2015. Research progress on conservation and restoration of biodiversity in land reclamation of opencast coal mine. Transactions of the Chinese Society for Agricultural Machinery 46, 72-82. https://doi.org/10. 6041./j. issn. 1000-1298. 2015. 08. 012.

Jan, N., Jean, P., Maude, V.P., et al., 2006. Assessment of gully erosion rates through interviews and measurements: a case study from northern Ethiopia, Earth Surface Processes and Landforms, 31(2),167-185.

Kainthola, A., Verma, D., Gupte, S.S., Singh, T.N., 2011. A coal mine dump stability analysisa case study. Geomaterials 1, 1-13.

Kennedy, B. A., 1990. Surface Mining, 2nd Edition. Colorado:Society of Mining,Metallurgy and Exploration Inc.

Khalil, A., Hanich, L., Hakkou, R., Lepage, M., 2014. GIS-based environmental database for assessing the mine pollution: A case study of an abandoned mine site in Morocco. Journal of Geochemical Exploration 144, 468-477. https://doi.org/10.1016/j.gexplo.2014.03.023.

Kršák B., Blišť an P., Pauliková A., Puskarova, P., Kovanic, L., Palkova, J., Zeliznakova, V., 2016. Use of low-cost UAV photogrammetry to analyze the accuracy of a digital elevation model in a case study. Measurement 91, 276-287. https://doi.org/10.1016/j.measurement.2016.05.028. 
Li, M.M., Wu, B.F., Yan, C.Z., Zhou, W.F., 2004. Remote sensing estimation of VFC in the upper reaches of Miyun reservoir. Resources Science 26, 153-159. https://doi.org/10.3321/j.issn:10077588.2004.04.022.

Liang, P., Yang X.P., 2016. Landscape spatial patterns in the Maowusu (Mu Us) Sandy Land, northern China and their impact factors. Catena 145, 321-333. https://doi.org/10.1016/j.catena.2016.06.023.

Liao, Y., Wang, X. Y., Zhou, J. M., 2016. Suitability assessment and validation of giant panda habitat based on geographical detector. Journal of Geoinformation Science 18, 767-778. https://doi.org/10.3724/SP.J.1047.2016.00767.

Liu, C.L., Wang, J.M., Bai, Z.K., Chen, D.Y., Zhang, S.L., 2011. Analysis of land reclamation technologies for surface coal mine in arid grassland. Metal Mine 5, 154-157.

Liu, X.Y., Bai, Z.K., Zhou. W., Cao, Y.G., Zhang, G.J., 2016. Changes in soil properties in the soil profile after mining and reclamation in an opencast coal mine on the Loess Plateau, China. Ecological Engineering 98, 228-239. https://doi.org/10.1016/j.ecoleng.2016.10.078

Liu, X.Y., Zhou. W., Bai, Z.K., 2016. Vegetation coverage change and stability in large open-pit coal mine dumps in China during 1990-2015. Ecological Engineering 95, 447-451. https://doi.org/10.1016/j.ecoleng.2016.06.051

Lü, G., Liu, Y.Z., Li, Y.X., Fu, X.Y., Wang, L., 2018. Spatial Variation Characteristics of Physical Properties of Surface Soil Moisture in Dump Slope of Haizhou Open-Pit Coal Mine[J]. Chinese Journal of Soil Science, 49(1), https://doi.org/69-77. 10.19336/j.cnki.trtb.2018.01.10

Lü, Z., Wang, D.M., Xu, Z.Y., Wang, W.J., 2013. Soil erosion characteristic and prevention measures in abandoned dreg (soil) field of production and construction. Science of Soil and Water Conservation 11, 118-126. https://doi.org/10.16843/j.sswc.2013.03.023

Martin Duque, J. F., Zapico, I., Oyarzun, R., López García, J.A., Cubas, P., 2015. A descriptive and quantitative approach regarding erosion and development of landforms on abandoned mine tailings: New insights and environmental implications from SE Spain. Geomorphology 239, 1-16. https://doi.org/10.1016/j.geomorph.2015.02.035

McHarg, I. L. 1969. Design with Nature. New York: John Wiley \& Sons.

Mendes, W.D., Neto, L.G.M., Dematte, J.A.M., Gallo, B.C., Rizzo, R., Safanelli, J.L., Fongaro, C.T., 2019. Is it possible to map subsurface soil attributes by satellite spectral transfer models? Geoderma 343,269-279. https://doi.org/10.1016/j.geoderma.2019.01.025

Messinger, M., Silman, M., 2016. Unmanned aerial vehicles for the assessment and monitoring of environmental contamination: An example from coal ash spills. Environmental Pollution 218, 889-894. https://doi.org/10.1016/j.envpol.2016.08.019 
Nearing, M., Jetten, V., Baffaut, C., Cerdan, O., Couturier, A., Hernandez, M., Le Bissonnais, Y., Nichols, M., Nunes, J., Renschler, C., 2005. Modeling response of soil erosion and runoff to changes in precipitation and cover. Catena, 61(2):131-154. https://doi.org/10.1016/j.catena.2005.03.007

Neugirg, F., Stark, M., Kaiser, A., Vlacilova, M., Della Seta, M., Vergari, F., Schmidt, J., Becht, M., Haas, F., 2016. Erosion processes in calanchi in the Upper Orcia Valley, Southern Tuscany, Italy based on multitemporal high-resolution terrestrial LiDAR and UAV surveys. Geomorphology 269, 8-22. https://doi.org/10.1016/j.geomorph.2016.06.027.

Nyssen, J., Poesen, J., Moeyersons, J., Deckers, J., Haile, M., 2006a. Processes and rates of rock fragment displacement on cliffs and scree slopes in an amba landscape, Ethiopia. Geomorphology $81,265-275$.

Nyssen, J., Poesen, J., Veyret-Picot, M., Moeyersons, J., Haile, M., Deckers, J., Dewit, J., Naudts, J., Teka, K., Govers, G., 2006b. Assessment of gully erosion rates through interviews and measurements: a case study from northern Ethiopia, Earth Surface Processes and Landforms 31, 167-185. https://doi.org/10.1002/esp.1317.

Nyssen, J., Vermeersch, D., 2010. Slope aspect affects geomorphic dynamics of coal mining spoil heaps in Belgium. Geomorphology 123, 109-121. https://doi.org/10.1016/j.geomorph.2010.07.004

Obade, V., Lal, R., 2013. Assessing land cover and soil quality by remote sensing and geographical information systems (GIS). Catena 104, 77-92. https://doi.org/10.1016/j.catena.2012.10.014.

Pan, J., Bai, Z.K., Cao, Y.G., Zhou, W. , Wang, J.M., 2017. Influence of soil physical properties and vegetation coverage at different slope aspects in a reclaimed dump. Environmental Science and Pollution Research 24(30),23953-23965. https://doi.org/10.1007/s11356-017-9974-5.

Petra, Z., Marian, M., Dominik, N., Jan, D., Roman, B., Jozef, V., 2015. Analysis of Possibilities of Reclamation Waste Dumps after Coal Mining. Procedia Earth and Planetary Science 15, 656662. https://doi.org/10.1016/j.proeps.2015.08.077.

Qi, X., 2017. Study on the effect of vegetation reconstruction and recovery on open-cast coal mine dump. Inner Mongolia: Inner Mongolia Agricultural University.

Ren H, Xiao W, Zhao Y.L, Hu Z.Q, 2020. Land damage assessment using maize aboveground biomass estimated from unmanned aerial vehicle in high groundwater level regions affected by underground coal mining[J]. Environmental Science and Pollution Research 27(17): 21666-21679.

Ren H, Zhao Y.L, Xiao W, Hu Z.Q, 2019. A review of UAV monitoring in mining areas: Current status and future perspectives[J]. International Journal of Coal Science \& Technology 6(3): 320-333.

Rodriguez Caballero, E., Canton, Y., Jetten, V., 2015. Biological soil crust effects must be included to accurately model infiltration and erosion in drylands: An example from Tabernas Badlands. Geomorphology 241, 331-342. https://doi.org/10.1016/j.geomorph.2015.03.042 
Sahle, M., Saito, O., Fuest, C., Yeshitela, K., 2019. Quantifying and mapping of water-related ecosystem services for enhancing the security of the food-water-energy nexus in tropical data-sparse catchment. Science of the Total Environment 646, 573-586. https://doi.org/ 10.1016/j.scitotenv.2018.07.347.

Schroeter, L., Glaesser, C., 2011. Analyses and monitoring of lignite mining lakes in Eastern Germany with spectral signatures of Landsat TM satellite data. International Journal of Coal Geology 86, 27-39. https://doi.org/10.1016/j.coal.2011.01.005.

Scorpio V., Crema S., Marra F., Righini, M., Ciccarese, G., Borga, M., Cavalli, M., Corsini, A., Marchi, L., Surian, N., Comiti, F., 2018. Basin-scale analysis of the geomorphic effectiveness of flash floods: A study in the northern Apennines (Italy). Science of the Total Environment 640, 337351. https://doi.org/10.1016/j.scitotenv.2018.05.252.

Shanxi provincial bureau of quality and technical supervision, 2016. Technical Specifications for mixed ecological filling with fly ash and coal gangue. http://www.doc88.com/p9929139475210.html. (accessed 4 November 2018).

Shivesh Kishore, K., Sukha Ranjan, S., Subodh Kumar, M., 2016. Assessment of the capability of remote sensing and GIS techniques for monitoring reclamation success in coal mine degraded lands. Journal of Environmental Management 182, 272-283. https://doi.org/10.1016/j.jenvman.2016.07.070

Siebert, S., Teizer, J., 2014. Mobile 3D mapping for surveying earthwork projects using an Unmanned Aerial Vehicle (UAV) system. Automation in construction 41, 1-14. https://doi.org/10.1016/j.autcon.2014.01.004

Sotiris, V., George, P., Athanassios, G., 2018. Mapping an earthquake-induced landslide based on UAV imagery; case study of the 2015 Okeanos landslide, Lefkada, Greece. Engineering Geology 245, 141-152. https://doi.org/10.1016/j.enggeo.2018.08.010.

Srinivasan Madhusudan, P., Bhatia, S., Shenoy, K., 2015. Vegetation-environment relationships in a South Asian tropical montane grassland ecosystem: restoration implications. Tropical Ecology 56, 201-217. https://doi.org/10.1126/science.2511632.

Tarolli, P., Sofia, G., 2016. Human topographic signatures and derived geomorphic processes across landscapes. Geomorphology 255, 140-161. https://doi.org/10.1016/j.geomorph.2015.12.007

Tomas, R., Romero, R., Mulas, J., Marturia, J. J., Mallorqui, J. J., Lopez-Sanchez, J. M., Herrera, G., Gutierrez, F., Gonzalez, P. J., Fernandez, J., Duque, S., Concha-Dimas, A., Cocksley, G., Castaneda, C., Carrasco, D., Blanco, P., 2014. Radar interferometry techniques for the study of ground subsidence phenomena: A review of practical issues through cases in Spain. Environment Earth Sciences 71, 163-181. https://doi.org/10.1007/s12665-013-2422-z 
Tong, L.G., Xu, X.L., Fu, Y., Wei, F.H., 2014. Impact of environmental factors on snail distribution using geographical detector model. Progress in Geography 33(5),625-635. https://doi.org/10.11820/dlkxjz.2014.005.004

Wang, J., Zhang, Y.N., Guo, Y.Q., 2014. Land reclamation and ecological reconstruction in mining area. Areal Research and Development 33, 113-116. https://doi.org/10.3969/j.issn.10032363.2014.06.021.

Wang, J.F., Li, X.H., Christakos, G., Liao, Y.L., Zhang, T., Gu, X., Zheng, X.Y., 2010. Geographical detectors-based health risk assessment and its application in the neural tube defects study of the Heshun region, China. International Journal of Geographical Information Science 24, 107-127. https://doi.org/10.1080/13658810802443457.

Wang, J.M., Lu, X., Feng, Y., Yang, R.X., 2018. Integrating multi-fractal theory and geo-statistics method to characterize the spatial variability of particle size distribution of minesoils. Geoderma 317, 39-46. https://doi.org/10.1016/j.geoderma.2017.12.027

Wang, J.M., Wang, H.D., Cao, Y.G., 2016. Effects of soil and topographic factors on vegetation restoration in opencast coal mine dumps located in a loess area. Scientific Reports 6, 22058. https://doi.org/10.1038/srep22058.

Wang, J.M., Zhang M., Bai Z.K., Yang, R.X., Guo, L.L., 2014. Multi-fractal characteristics of reconstructed soil particle in opencast coal mine dump in loess area. Transactions of the Chinese Society of Agricultural Engineering 30, 230-238. https://doi.org/10.3969/j.issn.10026819.2014.04.028.

Wischmeier, W.H., Smith, D.D., 1978. Predicting rainfall erosion losses: a guide to conservation planning. Washington D. C.: U. S. Department of Agriculture.

Xiao, W., Hu, Z.Q., Zhang, J.Y., Zhao, Y.L., Yang, K., 2017. The status and prospect of UAV remote sensing in mine monitoring and land reclamation. China Mining Magazine 26,71-78. https://doi.org/10.3969/j.issn.1004-4051.2017.06.014.

Xiao, W., Sui, T., Wang, X., Zhu, Q., Liu, R., Chen, X.Y., 2018. Assessment and geographical detection of heavy metal pollution in typical farmland soil in Chaohu Lake basin. Transactions of the Chinese Society for Agricultural Machinery 49, 144-152. https://doi.org/10.6041 /j. issn.10001298.2018.07.018.

Yang, Y., 2016. Study on spatial pattern of soil heavy metal and revegetation of Xilingol opencast coal mining. Inner Mongolia: Inner Mongolia Agricultural University. · ·

Yuan, Y., Zhao Z.Q., Zhang, P.F., Chen, L.M., Hu, T., Niu S.Y., Bai, Z.K., 2017. Soil organic carbon and nitrogen pools in reclaimed mine soils under forest and cropland ecosystems in the Loess Plateau, China. Ecological Engineering 102, 137-144. http://doi.org/10.1016/j.ecoleng.2017.01.028 Yuan, Y., Zhao, Z.Q., Li, X.Z., Wang, Y.Y., Bai, Z.K., 2018. Characteristics of labile organic 
carbon fractions in reclaimed mine soils: Evidence from three reclaimed forests in the Pingshuo opencast coal mine, China. Science of the Total Environment 613, 1196-1206. https://doi.org/10.1016/j.scitotenv.2017.09.170.

Zhang, J.Q., Yang, M.Y., Deng, X.X., Liu, Z., Zhang, F.B., 2019. The effects of tillage on sheet erosion on sloping fields in the wind-water erosion crisscross region of the Chinese Loess Plateau. Soil \& Tillage Research 187, 235-245. https://doi.org/10.1016/j.still.2018.12.014

Zhang, X.L., Zhao, Y., 2018. Identification of the driving factors' influences on regional energyrelated carbon emissions in China based on geographical detector method. Environmental Science and Pollution Research 25, 9626-9635. https://doi.org/10.1007/s11356-018-1237-6

Zhang, Z.D., Wieland, R., Reiche, M., Funk, R., Hoffmann, C., Li, Y., Sommer, M., 2012. Identifying sensitive areas to wind erosion in the Xilingele grassland by computational fluid dynamics modelling. Ecological Informatics 8,37-47. https://doi.org/10.1016/j.ecoinf.2011.12.002

Zhao, Z.Q., Cai, Y.L., Fu, M.C., Bai, Z.K., 2008. Response of the soils of different land use types to drought: Eco-physiological characteristics of plants grown on the soils by pot experiment. Ecological Engineering 34, 215-222. https://doi.org/10.1016/j.ecoleng.2008.08.003.

Zhao, Z.Q., Shahrour, I., Bai, Z.K., Fan, W.X., Feng, L.R., Li, H.F., 2012. Soils development in opencast coal mine spoils reclaimed for 1-13 years in the West-Northern Loess Plateau of China. European Journal of Soil Biology 55, 40-46. http://dx.doi.org/10.1016/j.ejsobi.2012.08.006.

Zhao, Z.Q., Xi, M.Z., Jiang, G.Y., Liu, X.N., Bai, Z.K., Huang, Y.Z., 2010. Effects of IDSA, EDDS and EDTA on heavy metals accumulation in hydroponically grown maize (Zea mays, L.). Journal of Hazardous Materials 181, 455-459. https://doi.org/10.1016/j.jhazmat.2010.05.032.

Zhao Y.L, Zheng W.X, Xiao W, Zhang S, Lv X.J, Zhang J.Y, 2020. Rapid monitoring of reclaimed farmland effects in coal mining subsidence area using a multi-spectral UAV platform[J]. Environmental Monitoring and Assessment 192(7): 1-19.

Zhou, W., Yang, K., Bai, Z.K., Cheng, H.X., Liu, F., 2017. The development of topsoil properties under different reclaimed land uses in the Pingshuo opencast coalmine of Loess Plateau of China. Ecological Engineering 100, 237-245. http://dx.doi.org/10.1016/j.ecoleng.2016.12.028. 
Figures

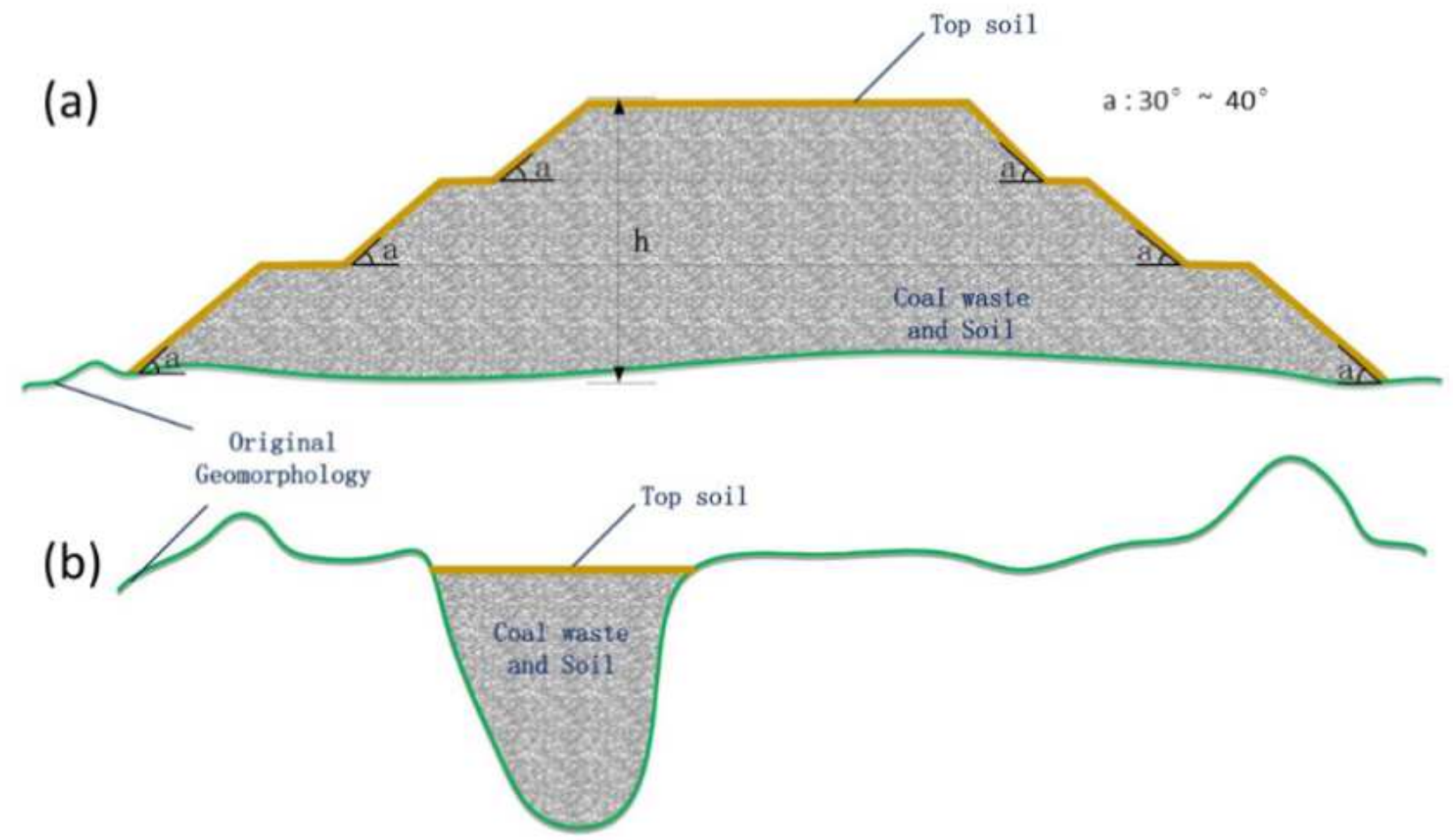

Figure 1

Waste dump diagram. (a) Multi-stage dump. (b) Gully filled dump. 


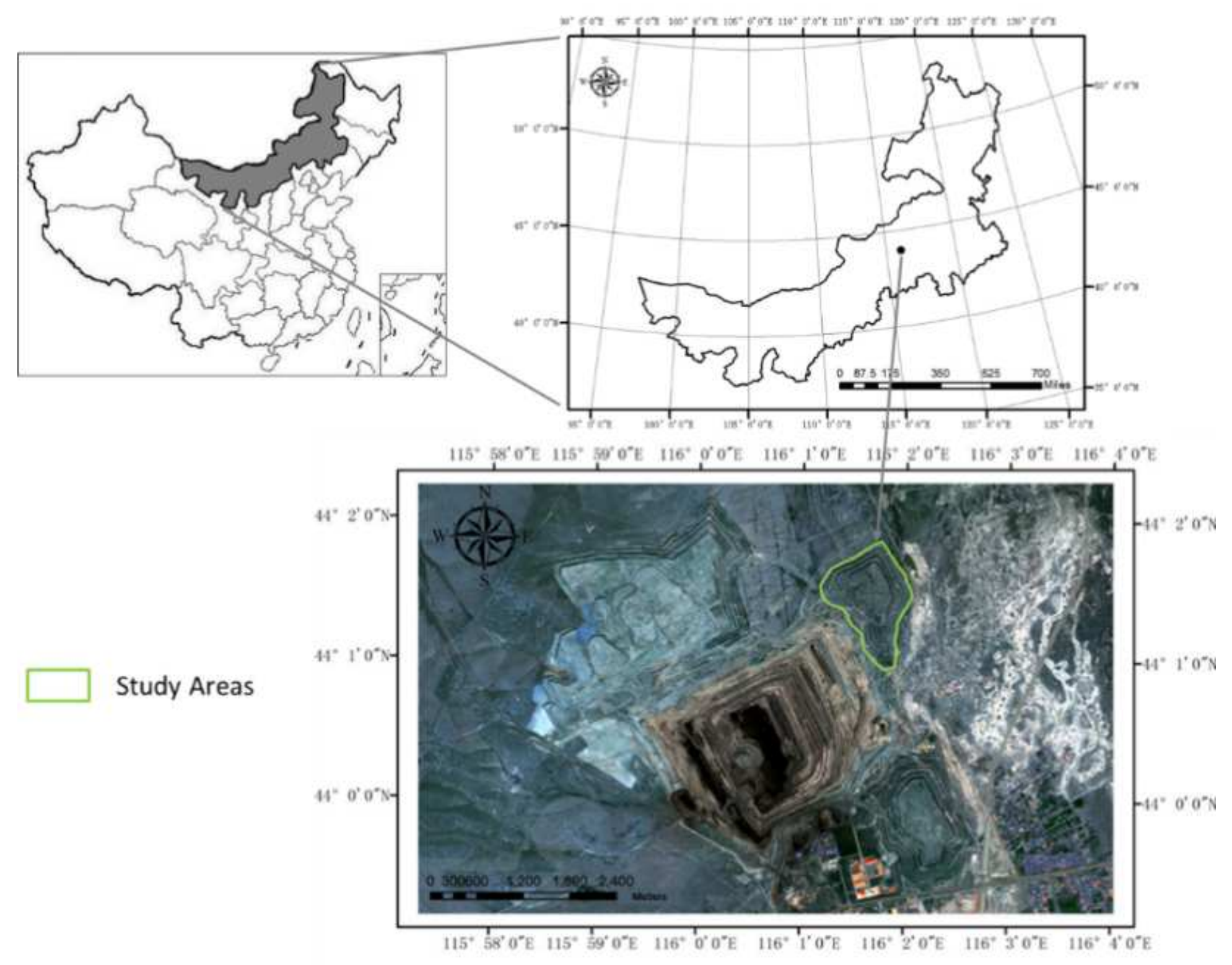

Figure 2

The study area location. Note: The designations employed and the presentation of the material on this map do not imply the expression of any opinion whatsoever on the part of Research Square concerning the legal status of any country, territory, city or area o bbnhjr of its authorities, or concerning the delimitation of its frontiers or boundaries. This map has been provided by the authors. 


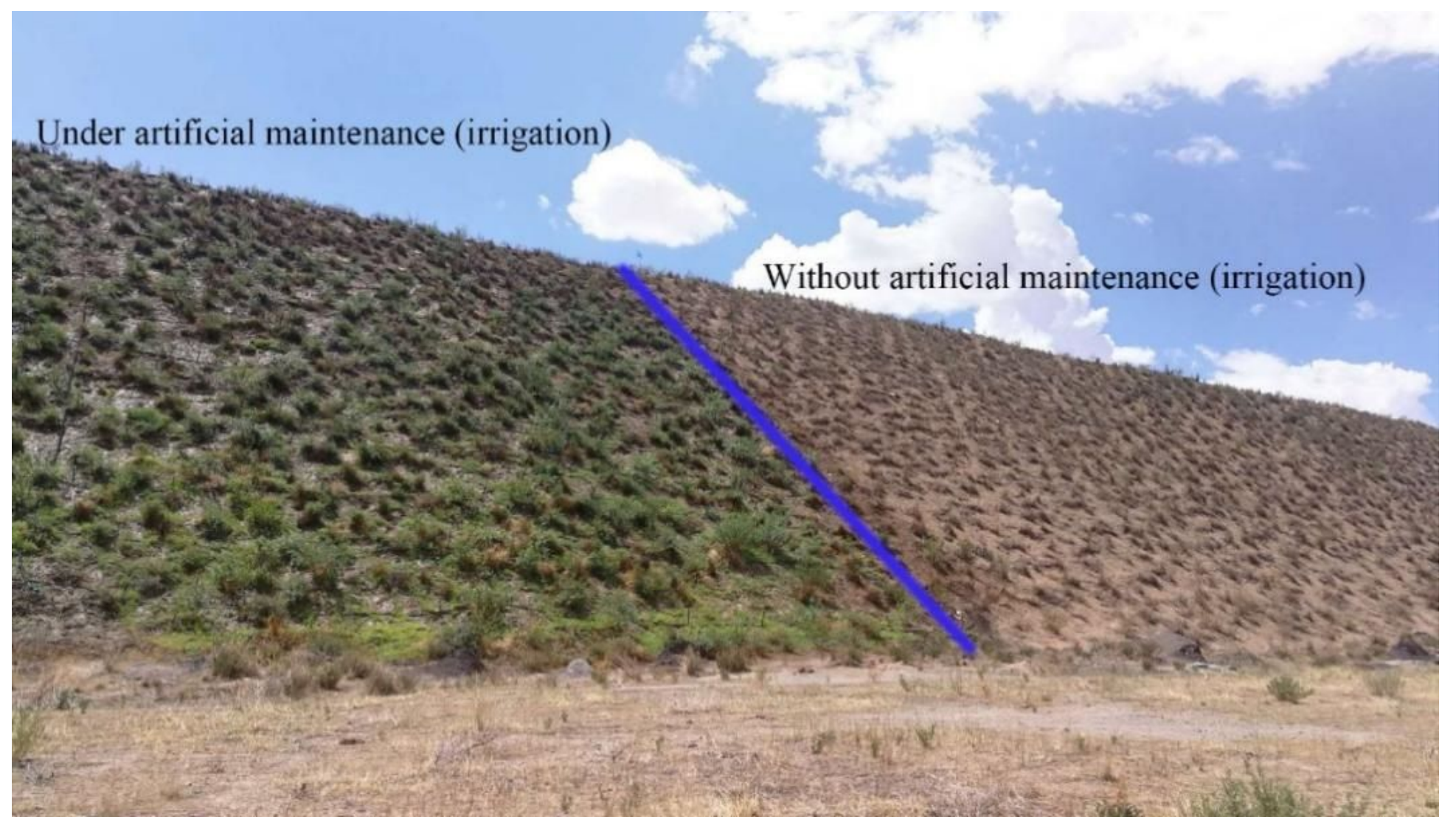

\section{Figure 3}

A comparison of dumps with and without artificial maintenance in the south dumps of Shengli coal field. 


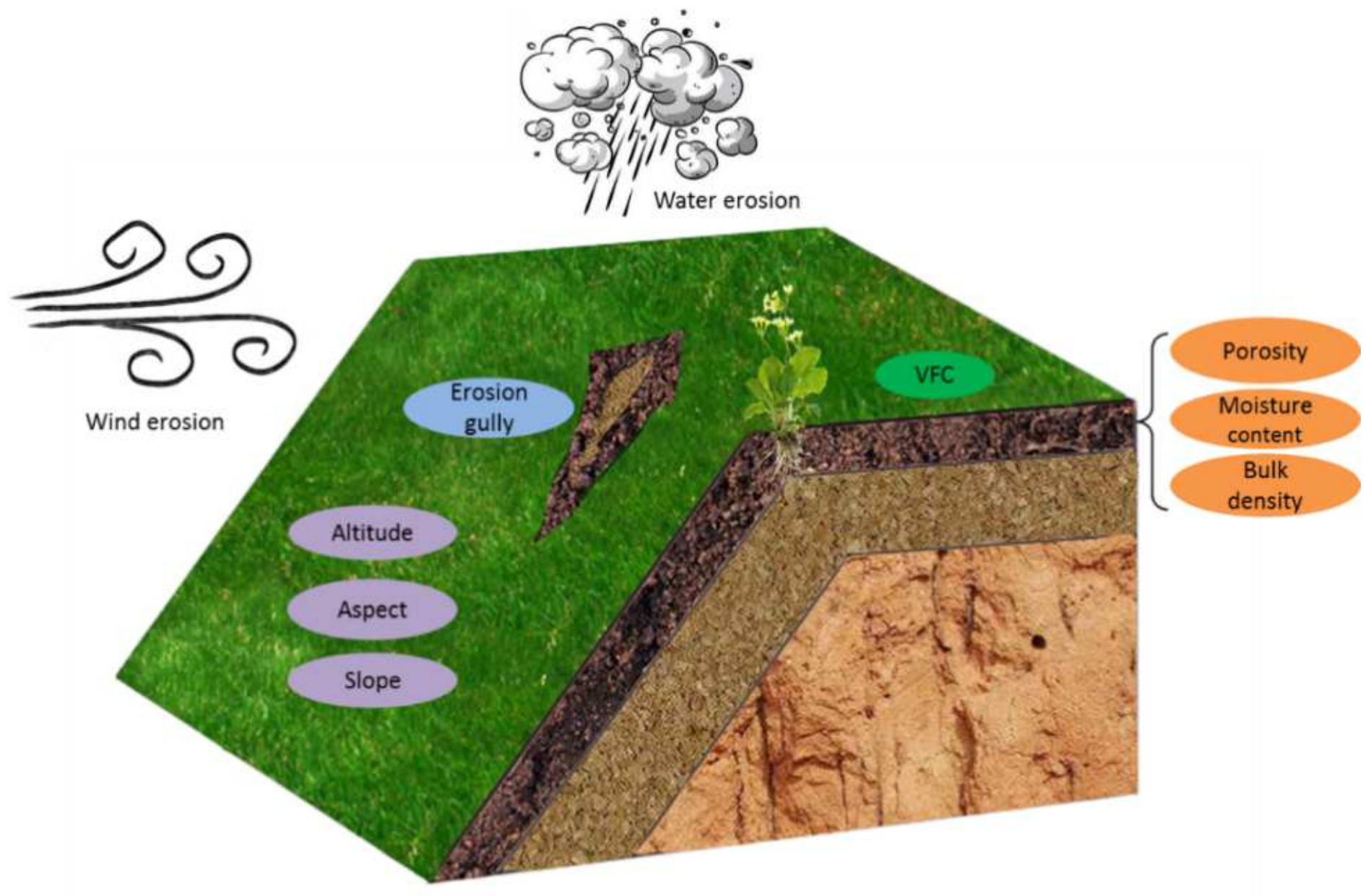

Figure 4

Potential impact of wind and soil erosion on coal mine dumps under natural conditions. 


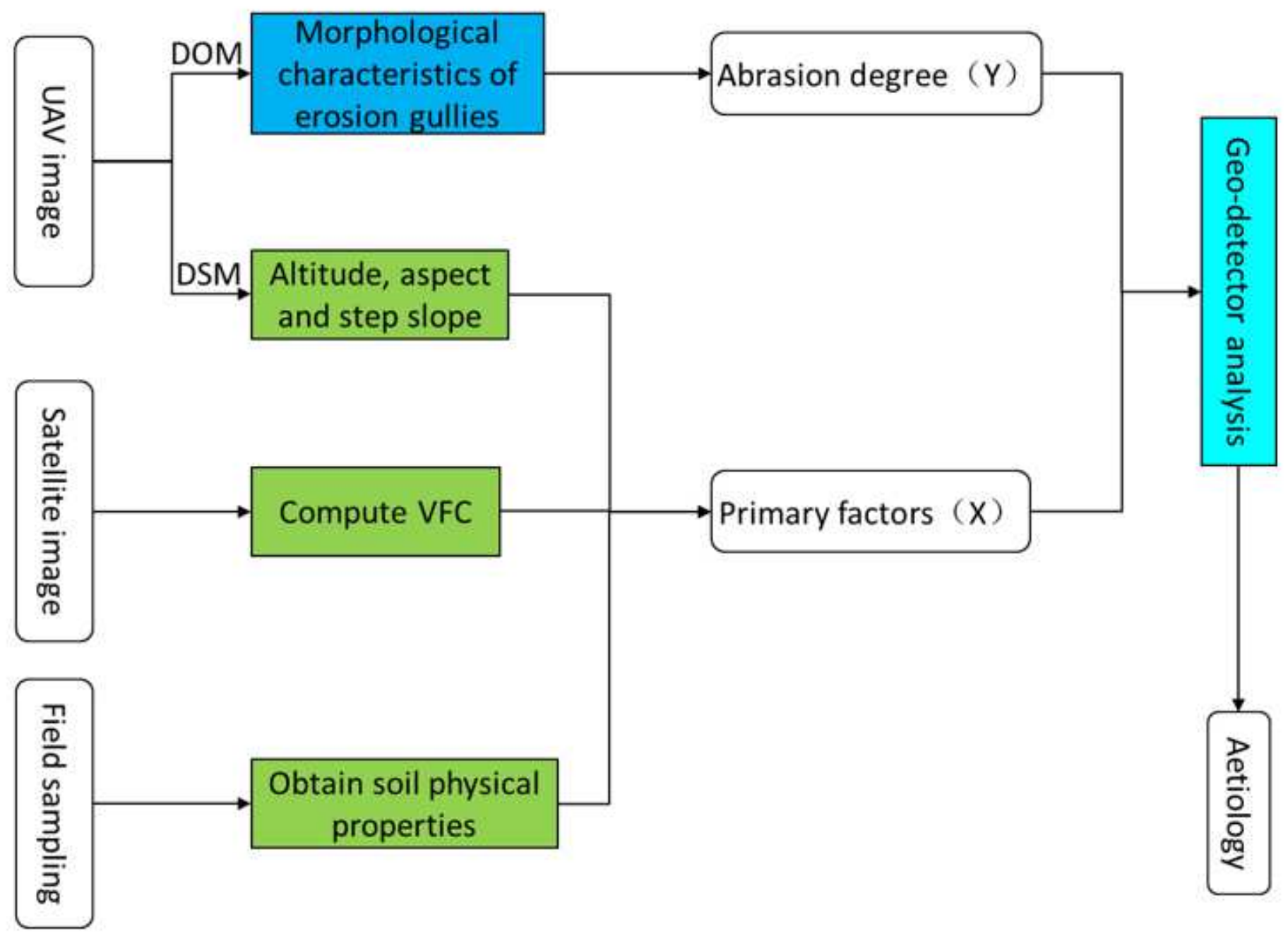

Figure 5

Methodology flow chart. 


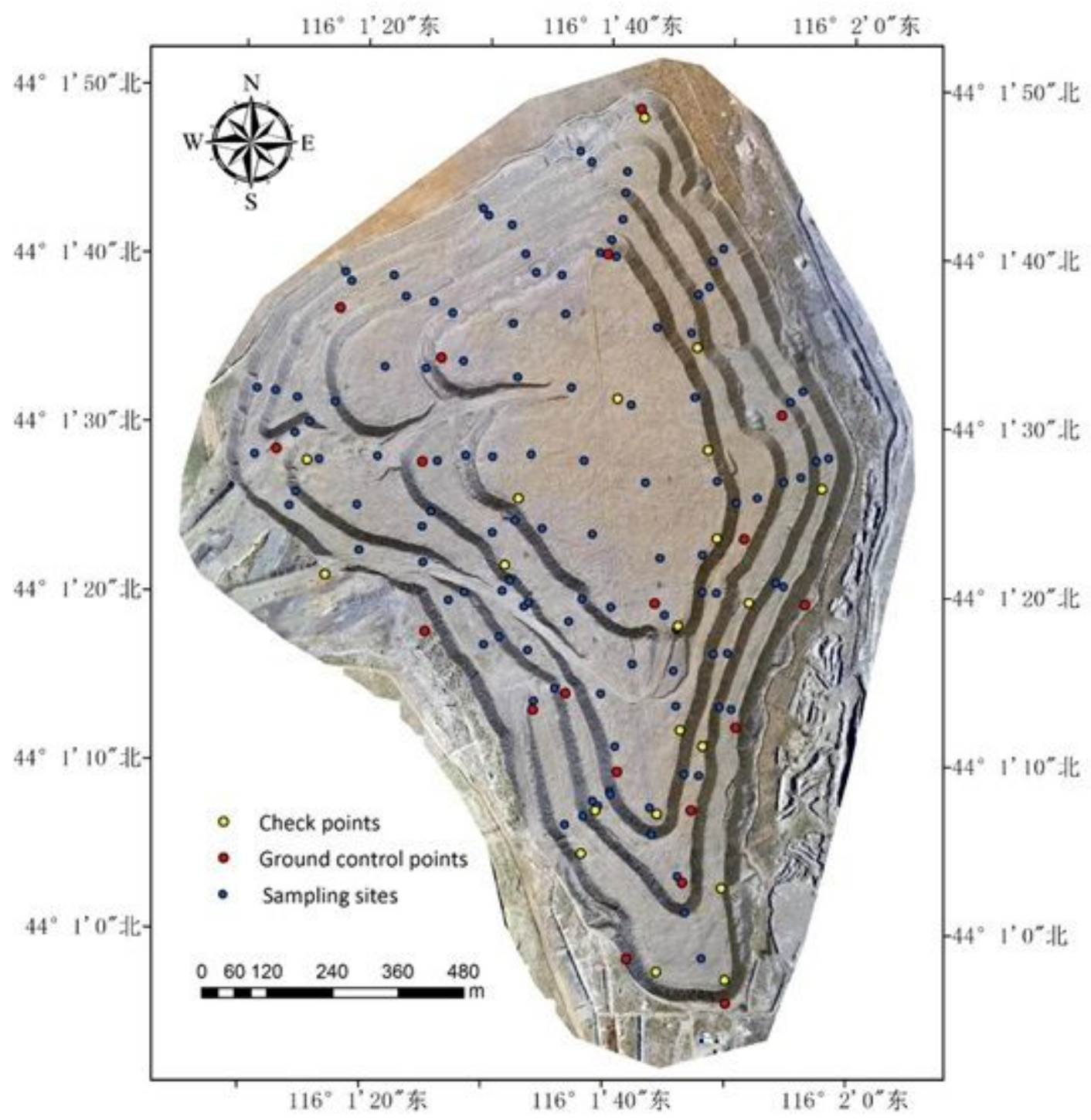

Figure 6

Sketch map of ground control points, control points and sampling sites. 


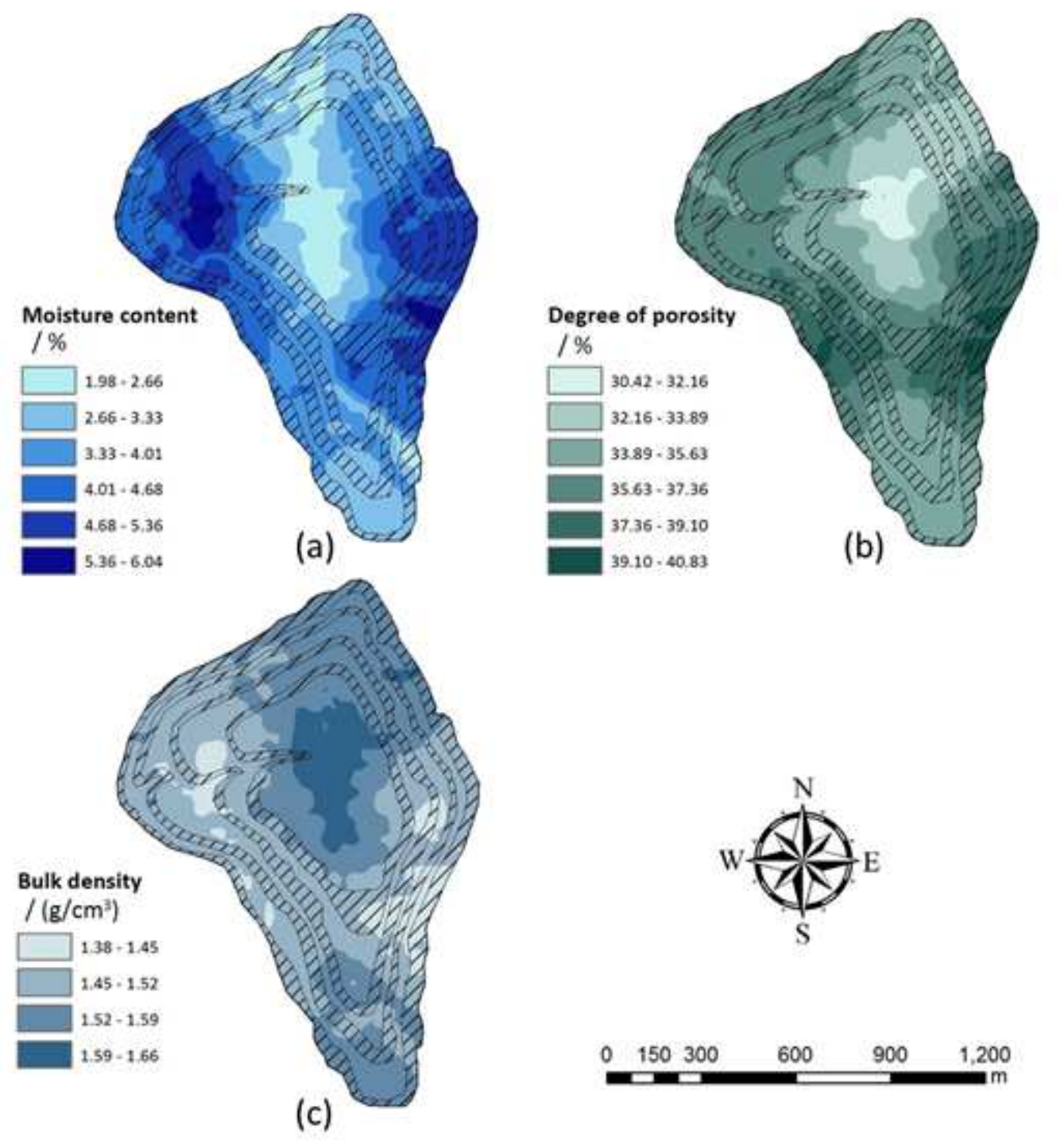

Figure 7

Soil physical properties. (a) Moisture content. (b) Degree of porosity. (c) Bulk density. 


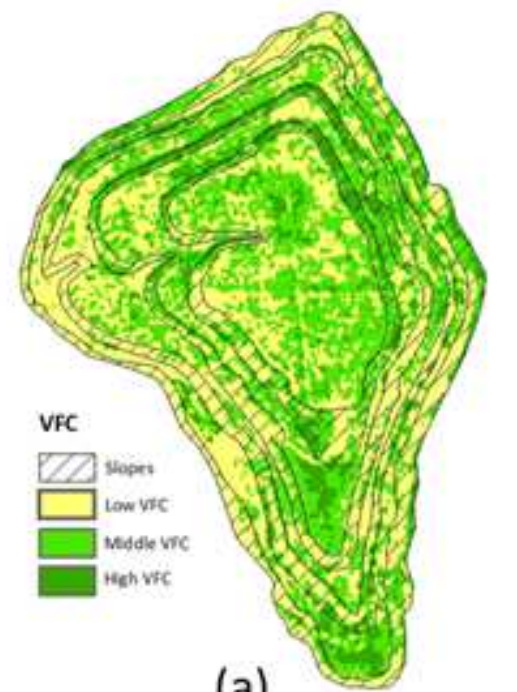

(a)

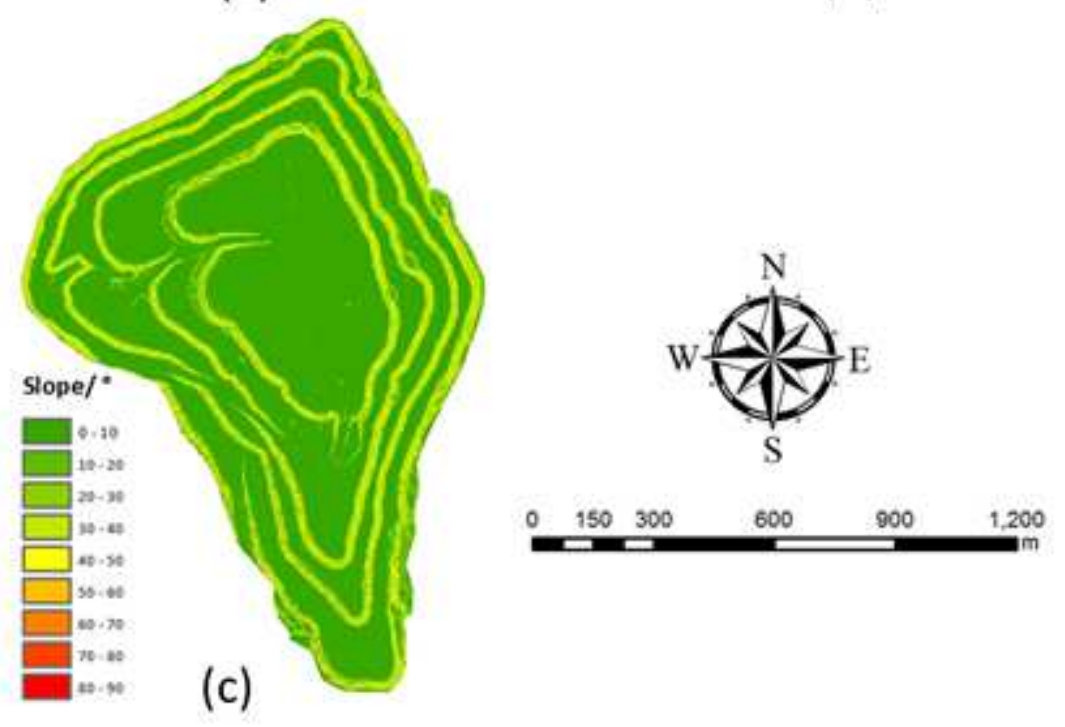

Figure 8

VFC, Slope aspect and gradient. (a)VFC. (b) Aspect. (c) Gradient. 


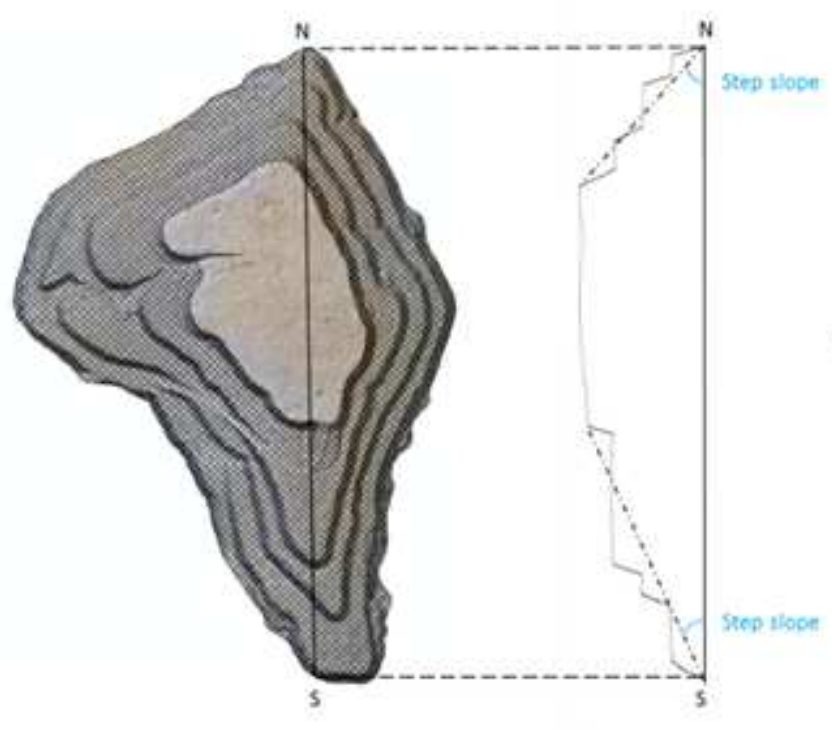

(a)

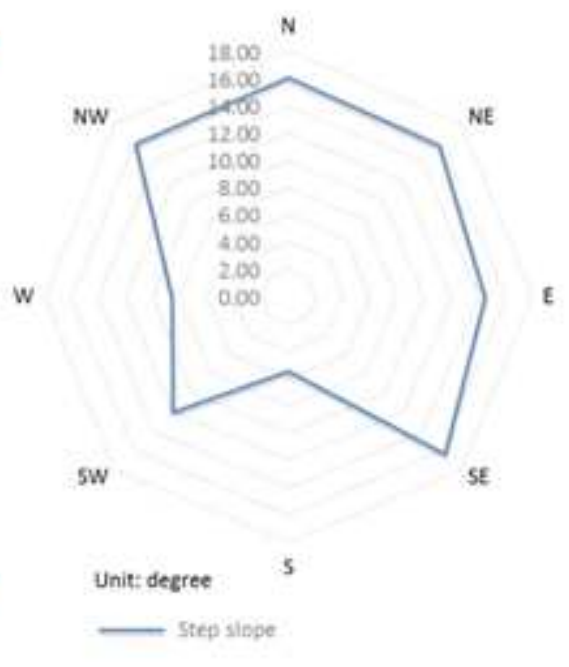

(b)

Figure 9

Step slope. (a) The elevation profile from the DSM is shown on the right, with its location shown on the map on the left. (b) Radar chart of the step slope gradient.

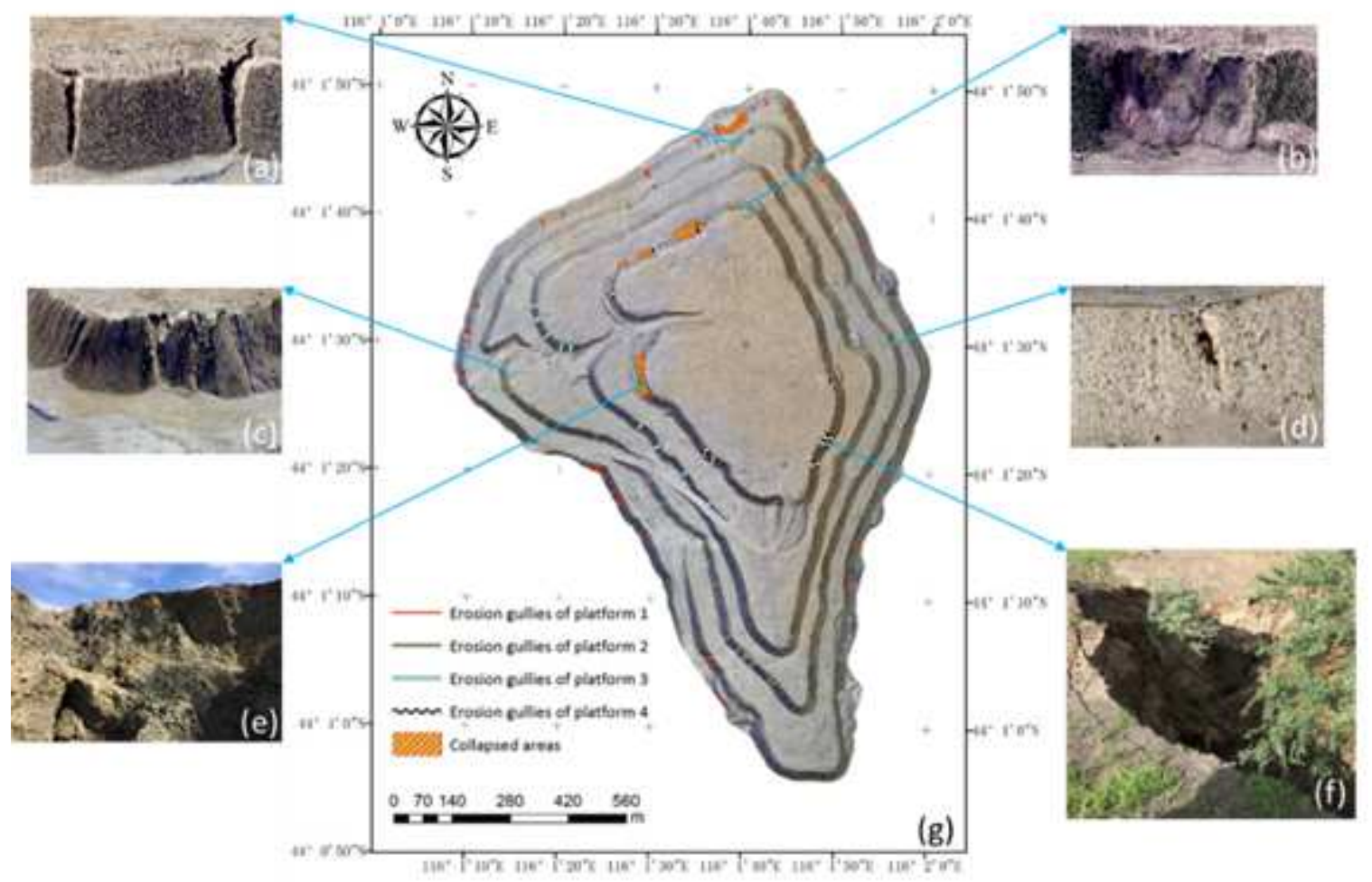

Figure 10

Geologic hazards at north dump. (a-d) Hazards shown in 3D models. (e-f) Photos taken in the field. (g) Distribution of hazards. 

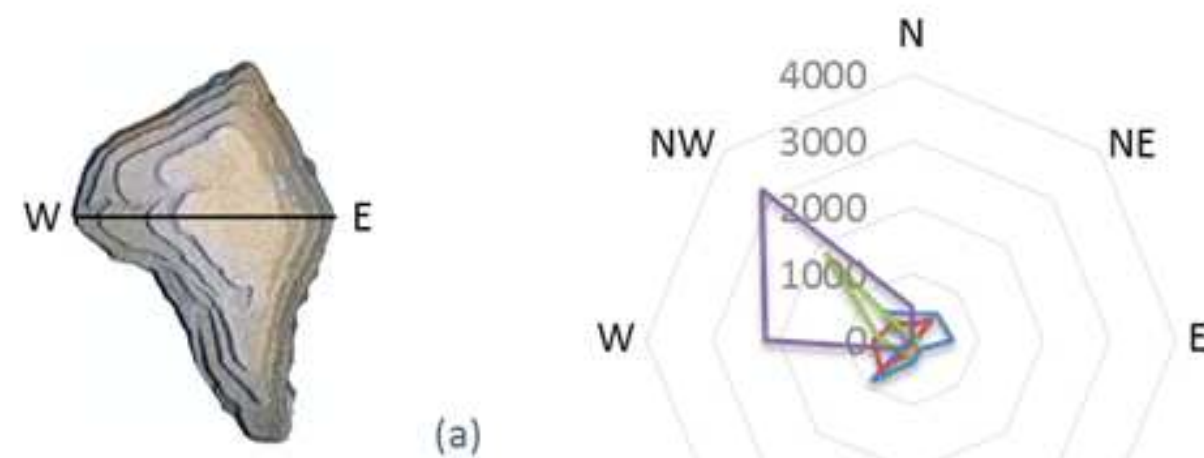

(a)

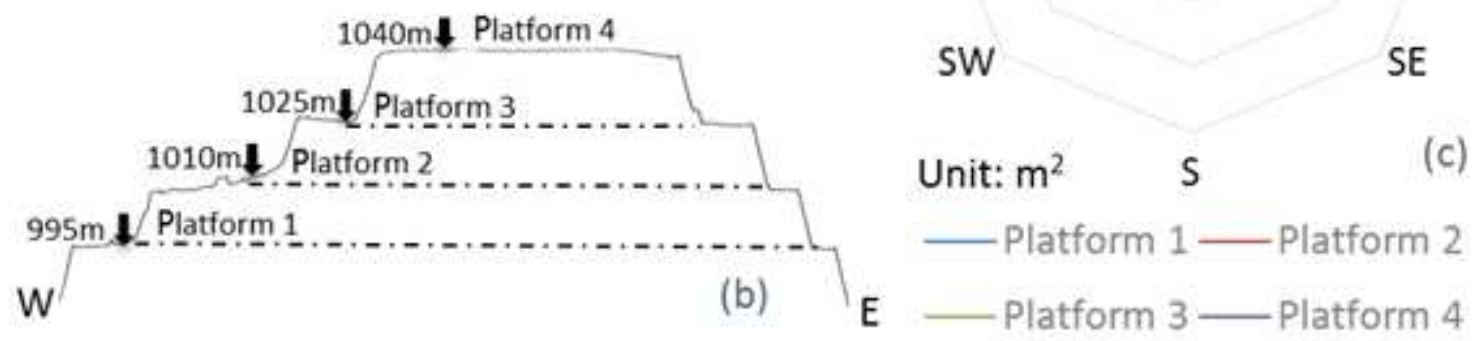

Figure 11

Erosion gullies radar chart. (a) Section line. (b) Transverse section. (c) Radar chart of erosion extent of each platform: the distance from the center represents the erosion extent.

\section{Power of determinant}

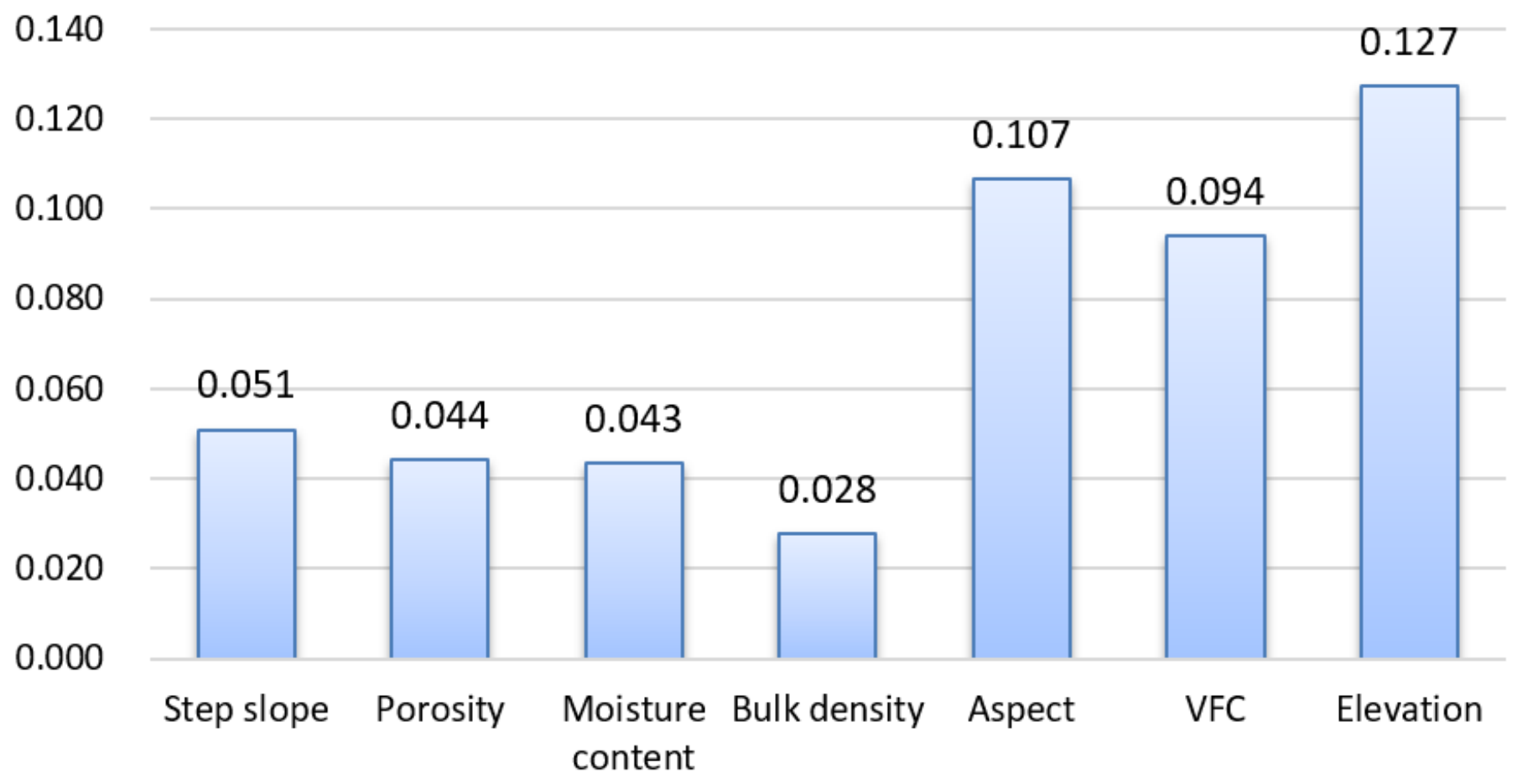


The influences of different driving factors on the degree of erosion. 